\title{
LA EXTREMADURA MUSULMANA (1142-1248) ORGANIZACIÓN DEFENSIVA Y SOCIEDAD
}

\author{
Julián Clemente Ramos \\ Universidad de Extremadura (Caceres)
}

\begin{abstract}
SUMARIO
1. Extremadura como realidad fronteriza.- 2. La estructura defensiva.- 3.

El. espacio.- 4. Estructuras sociales y económicas.- 5. Conclusiones.
\end{abstract}

Dentro de la dominación musulmana de Extremadura, la conquista de Coria en 1142 marca una etapa importe'. Anteriormente ya habla sido conquistada por Alfonso VI, que de este modo esperaba tener una solida frontera en el Tajo tanto en la parte occidental como oriental de su reino; pero esta primera dominación cristiana fue efímera. La segunda y definitiva conquista la realiza Alfonso VII y nunca más volverá esta ciudad extremeña a ser controlada por los musulmanes. Esta conquista se produce en el momento de la disgregación almorávide. Entre este momento y el asentamiento sólido de los almohades en la península, los cristianos realizan numerosos avances; pero Coria, y por tanto el establecimiento del Tajo como frontera en la actual Extremadura, es uno de los pocos que pudieron conservarse. Esta ciudad jugará un papel clave en la Transierra leonesa al ser el ele-

${ }^{1}$ En general para la introducción pueden consultarse las obras de J. GONZALEZ, Regesta de Femando II, Madrid, 1942; Alfonso IX, 2 vols., Madrid, 1944; El reino de Castilla en la época de Alfonso VIII, 3 vols., Madrid, 1960; y Reinado y Diplomas de Femando III, 3 vols., Córdoba, 1980, 1983 y 1986.

"Anuario de Estudios Medievalos", 24 (1994) 
mento central de toda su estructura defensiva ${ }^{2}$. De hecho será el único concejo importante de la zona. Respecto de la zona nororiental de Extremadura, el poblamiento de Plasencia tiene unas consecuencias similares a la conquista de Coria, con la diferencia de que esta ciudad era una antigua urbs romana muy importante durante la dominación musulmana, mientras que Plasencia significaba tomar posesión de un despoblado en un intento de controlar una tierra de nadie. Conquistada Coria y asentada Plasencia ${ }^{3}$, el norte del Tajo se convertirá en una tierra en la que el control cristiano estará sólidamente establecido, al menos en lo relativo a su vertiente política y militar, dado su escaso poblamiento y endeblez demográfica.

Tras la conquista de Coria se abre, por tanto, un periodo que llega hasta el hundimiento total del dominio musulman en toda Extremadura. La Extremadura musulmana se convierte en una zona de frontera. Durante decenios representará una cuña (que se extiende también por Portugal) en tierra cristiana en la zona occidental de la península . Lisboa está a la misma altura de Badajoz, centro político y militar de la región, y en la zona castellana la frontera, como en todos sitios oscilante, pasará por momentos, antes de Las Navas de Tolosa, el río Guadiana. Extremadura es de este modo una auténtica marca fronteriza y algunas de las más importantes expediciones almohades, como la de 1197, cuyo destino era sin embargo Toledo, utilizarán caminos extremeños.

Dada la situación geopolítica de Extremadura no es raro que sea escenario de importantes enfrentamientos militares entre los diversos poderes que se asoman a la región: Portugal, León, Castilla y los almohades. Esta situación propiciará la existencia de pactos cambiantes. De hecho, la fugacidad de los mismos será una de sus claras características. De todos

\footnotetext{
${ }^{2}$ A. RECUERO ASTRAY, Alfonso VII, emperador. El imperio hispánico en el siglo XII, León, 1979, pag. 166, sitúa la conquista de Coria dentro del deseo de "completar el fortalecimiento de la frontera meridional". M. R. MARTINEZ y MARTINEZ, Historia del reino de Badajoz, durante la dominación musulmana, Badajoz, 1904, p. 225, considera que la conquista de Coria deja abierta la Extremadura musulmana "a las excursiones de los cristianos fronterizos".

${ }^{3} \mathrm{Si}$ bien su fundación no se debe tanto a la amenaza musulmana como al deseo de apuntalar la frontera con León, no dejo de cumplir esta función. Como reconoce B. PALACIOS MARTIN, Fundación y organización de Plasencia, "I Congreso de Historia sobre Plasencia y su tierra", pag. 3 (ponencia inédita) "era evidente la oportunidad de una plaza fucrte tras el Tajo que cubriera la espalda a las fortalezas avanzadas de Trujillo, Monfragüe y Montánchez, que hacía un año tan solo habían pasado del dominio leonés al castellano".
} 
estos poderes, el que parece ser más débil es Portugal ${ }^{4}$. Además, dado que en líneas generales la expansión de los reinos cristianos respeta la orientación norte/sur, la actual Extremadura quedaba fuera de sus zonas de legitima conquista. Sin embargo, León y Castilla se reconocían derechos sobre la misma sancionados en pactos realizados por estos dos reinos peninsulares. Castilla aspiraba a dominar la parte oriental extremeña y León, la occidental ${ }^{5}$. Ante estos dos poderes Portugal contaba con pocas posibilidades. El fracaso de Geraldo Sempavor, y por ende del rey portugués Alfonso Enriquez (Badajoz, 1170), significa el fracaso del Portugal en su intento de asomarse a la región extremeña ${ }^{6}$.

Ya hemos señalado que, con ciertas matizaciones, el Tajo pasa a ser la frontera cristiano/musulmana en Extremadura. Hasta después de Las Navas de Tolosa no habrá dominios cristianos solidamente establecidos al sur de este rio. Sin embargo, es una frontera flexible y oscilante, como la de las restantes zonas peninsulares. Las excepciones a la norma señalada vienen dadas por Alcántara, el señorío de Fernando Rodríguez el Castellano (que inicialmente lo disfruta como persona al servicio de los almohades) y las conquistas de Geraldo Sempavor, de las cuales una parte irán a parar, provisionalmente, al rey leonés Fernando II. En igual sentido, la mitad nororiental de la actual provincia de Cáceres puede considerarse una tierra de nadie hasta la fundación de Plasencia, aunque su ubicación al norte del Tajo hacia difícil para los musulmanes ocuparla de modo efectivo.

Si hacemos un desarrollo cronológico de la evolución de la frontera cristiano-musulmana en Extremadura desde la conquista de Coria hasta Las Navas de Tolosa, debemos señalar que 1142, fecha de la definitiva conquista cristiana de esta ciudad, significa para los musulmanes la pérdida del

\footnotetext{
"Incluso se produce un intento de repartir dicho reino (de iure un condado aún) entre León y Castilla en la paz de Sahagún (1158); la solución para Portugal viene con la paz de Lerez (1165), cuando se pacta el matrimonio del rey leonés, Fernando II, con una hija del monarca luso, Urraca Alfonso (J. GONZALEZ, Femando II, pp. 33 y 68-9).

5 En la paz de Sahagún, Sancho III y Femando II deciden considerar la calzada de la Guinea como la frontera de sus reinos entre el Sistema Central y el Tajo, según ya la señaló Alfonso VII, padro de ambos. De este modo, Badajoz, Mérida o Montánchez quedaban del lado leonés (J. GonZALEZ, Femando II, doc. 1, p. 243).

- En 1165, Alfonso Enríquez llega a controlar al oeste del Guadiane Alconchel, Mora y Serpa, lo que muestra sus intereses expansivos (M. R. MARTINEZ Y MARTfNEZ, lbid., p. 228). La derrota de Alfonso I en 1170 en las puertas de Badajoz y la posterior muerte de Geraldo Sempavor acabaron con los deseos portugueses de expansión en la actual Extremadura.
} 
control sobre el espacio que se extendía entre el Sistema Central y el Tajo, y que tras la conquista de Toledo se había convertido en una cuña musulmana. Esta frontera parece ser aceptada sin problemas por los musulmanes. De hecho no hay ningún intento sistemático de volver a dominar la citada ciudad extremeña. Sin embargo, cualquier intento cristiano de controlar fortificaciones sobre este río o más al sur originará una inmediata reacción (Cáceres, Alcántara, Trujillo). Esta situación significaba la posibilidad efectiva de Castilla de poblar la parte oriental, lo que hace con Plasencia. Si bien esto genera el descontento musulmán, esta zona era indefendible para los mismos y de hecho tras la destrucción de esta ciudad en 1196 no hay ningún intento de poblarla. Los almohades preferían ver esta zona como una tierra de nadie.

El Tajo aparece en la zona extremeña, por tanto, como un límite territorial aceptable por los musulmanes. Quizás pensasen que Coria estaba muy al norte y que la estructura defensiva de este territorio no estaba suficientemente estructurado como para poder mantener su control. En cualquier caso, los cristianos, con su tradicional avidez, no consideraron nunca este río como un frontera admisible. Para ellos solo era transitoria y los intentos de conquistas al sur del Tajo se suceden a lo largo de los años. Esto hacia necesario consolidar la frontera. Hasta la reaccion musulmana que sigue a la derrota del rey Lobo de Murcia (1172), la Extremadura musulmana tiene una gran debilidad defensiva, lo que nos hace pensar que no estaba preparada para la nueva situación creada y a su vez refleja la gran importancia estratégica que debió tener Coria. Alcántara en 1166 será presa fácil para Fernando II. Pero sobre todo, son las conquista de Geraldo Sempavor la que nos hablan de una zona defensivamente desestructurada, pese a ser una cuña que se introducía en los territorios cristianos. Por ello, Alcántara, Cáceres, Montánchez, Trujillo, Santa Cruz, así como otras plazas portuguesas muy próximas a la región extremeña serán controladas transitoriamente por Fernando II (la primera) y Geraldo Sempavor. Incluso Badajoz, centro estructurador del territorio, estuvo a punto de caer en 1169 en manos de este aventurero portugués, y si no lo hizo no fue por los almohades sino por Fernando II, que no estaba dispuesto a que fuera conquistada por ningún cristiano que no fuera él. Por tanto, hacia 1170, la frontera cristiano-musulmana prácticamente se sitúa en las estribaciones extremeñas de los Montes de Toledo, pues la ayuda a los almohades de Fernando II no fue gratuita. El rey leonés controla en estos momentos Alcántara y Cáceres, 
además de otras posesiones aisladas más al sur?. Trujillo, Santa Cruz, y Montánchez irán a parar a Fernando Rodríguez el Castellano, a la sazón al servicio de los almohades en este momento. Hay que esperar a 1174 para que el rey leonés pierda las plazas que tiene al sur del Tajo, plazas que se constituirán durante varias décadas, junto con Trujillo, en la llave defensiva de Extremadura. El Tajo vuelve a ser ahora frontera, aunque de iure más que de facto: el señorfo de el Castellano irá por medio de su hijo a parar a Castilla. Sólo después de 1196 Alfonso VIII perderá estas posesiones.

La expedición de 1174 marca una nueva etapa en la frontera. Los musulmanes, con una clara idea de la importancia estratégica de Extremadura, se dedican a fortificar sólidamente los puntos importantes. Desde entonces, la frontera musulmana se caracteriza por su solidez, incluso después de Las Navas de Tolosa. En este contexto de solidez defensiva musulmana, y tras la batalla de Alarcos (1195) y el subsecuente predominio almohade, se explica la conquista de los territorios detentados por el Castellano que habran pasado a Castilla en 1196, lo que devuelve la frontera al Tajo. Hasta el derrumbamiento almohade, los cristianos no vuelven a controlar en Extremadura ningún punto fortificado al sur de este río. Extremadura se habia transformado en una sólida marca fronteriza. Esto se demostrará no tanto entre Alarcos (1195) y Las Navas (1212), periodo de claro predominio almohade, cuanto después del derrumbamiento almohade: las dificultades sufridas para la conquista de Cáceres revelan la efectividad de los trabajos defensivos almohades en la región.

${ }^{7}$ En 1171, Femando II da a la orden de Santiago el castillo de Alconchel, "quod est ultra Badallocim apte situm ad expugnandos christi crucis inimicos" e "istas ereditates quae sunt infra terminos de Badallozzo, videlicet: vallem de Albuera cum Luchena, et Cantinnanam, et illud Castellum, quod dicitur Mons Maior cum illo rivo que vocatur Cadia, sicut defluit in Guadianam" (A. F. AGUADO DE CORDOBA, Bullarium equestris ordinis Sancti lacobi de Spatha, Madrid, 1719, doc. V. 2, p. 7, y IV, p. 6). El último documento citado ec data "in Xerit"; M. TERRON ALBARRAN, Extremadura musulinana. Badajoz, 713-1248, Badajoz, 1991, p. 182, no está de acuerdo con J. Gonź́lez en considerar este lugar Jerez de los Caballeros, sino que cree que se trata de un castillo situado junto al arroyo Morcillo, no lejos de Coria. Según él, J. GonzÁleZ (Alfonso IX, II, doc. 176, pp. 248-249) señalaría la ubicación del castillo, pero en dicho documento simplemente se alude al no Jerte, cuya desembocadura esta cerca de la Atalaya de Pelayo Velidiz. 


\section{EXTREMADURA COMO REALIDAD FRONTERIZA}

Dada la nueva situación geopolítica creada en la segunda mitad del siglo XII, Extremadura se convierte en una especie de marca debido a la política de reforzamiento defensivo llevada a cabo por los almohades ${ }^{8}$. Estos tienen una conciencia clara de que los momentos en que las zonas ocupadas por los musulmanes estaban fuera del radio de accion normal de los cristianos habían pasado no solo para la zona manchega, sino también para la extremeña. Ibn Said, historiador musulmán de esta época, lo dice con claridad: atribuye a un deseo de prevención "para lo que se temía de ataques y asedios" las labores defensivas llevadas a cabo en la alcazaba de Badajoz por orden de Abu Yaqub'. Se habra desarrollado en la zona una sensación de inseguridad no tanto por las expedicionès ocasionales que antes de la conquista de Coria y durante el reinado de Alfonso VII habían sido realizadas en la región por los cristianos, y que serían poco más que meros actos de pillaje ${ }^{10}$, como por la situación creada tras la carda de Coria y la endeblez defensiva de una zona que ahora estaba en plena frontera al no dominar los musulmanes puntos al norte del Tajo ${ }^{11}$. En cualquier

\footnotetext{
8 Esto no significa que antes no existieran abundantes fortificaciones en la zona, sino solamente que ahora se preparan para cumplir la nueva función que tienen. Veamos algunos ejemplos de lo primero: Al-Bakri dice que "Tuvo Badajoz distritos y fortalezas numerosas" y cita varios castillos de Mérida "y otros que sería largo enumerar" (M" Angeles PÉREZ ALVAREZ, Fuentes árabes de Extremadura, 2 vols., Cáceres, 1990 (tesis doctoral en prensa; en adelante citaremos simplemente como Fuentes), I, pp. 110 y 109; Ibn al-Kardabus señala como Femando I tomó "numerosos castillos del distrito de Badajoz" (F. MÁllo SALGADO, Historia de Al-Andalus (trad. del kitab al-iktifa), Madrid, 1986, p. 97; Ibn Idari también alude a lo mismo en relación con las conquistas de al-Mutadid y Femando I (Fueñtes, I, pp. 394 y 397).

9 IBN SAHIB AL-SAlA, Al-Mann bi-l-imana (trad. de A. Huici Miranda), Valencia, 1969, p. 149). Repite la misma idea Ibn Idari (Fuentes, I, 404).

10 Estamos informados de como los salmantinos "vastaverunt totam illam regionem, et fecerunt magnas strages et incendia et magnam captivationem virorum et mulierem et parvularum, et total supellectilem domorum et locupletationem auri et argenti abundanter insuper ceperunt opes magnas, equos et mulos, camellos et asinos, bobes et vaccas et omnia pecora campi" (Chronica Adephonsi imperatoris, Madrid, 1961 edic. de L. SANCHEZ BEIDApp. 95-96).

"M. R. MARTINEZ Y MARTtNEZ, Ibid., pp. 224 y 225, habla tras la conquista de Coria de una situación de "verdadera anarquía", en la que "los pueblos apenas tenían fuerzas para resistir a las mesnadas de cualquier concejo cristiano". No deja de haber expediciones en este momento on la Extremadura musulmana: on 1161 una lápida sepulcral de Bedajoz nos habla de que el alfaquí Abulcasem Talaf "padeció martirio en la parte oriental de la aljama de Badajoz cuando le sorprendió el enemigo en tiempo de paz",
} 
caso, con o sin solidez defensiva, la situación geoestratégica de la zona habra cambiado y la política almohade responderá a esta nueva realidad.

Inicialmente, como ya hemos señalado podemos hablar de una cierta endeblez de las defensas de la zona, lo cual es explicable si se tiene en cuenta que el papel que con el tiempo cogerán Cáceres o Trujillo como auténticas llaves defensivas de la frontera extremeña parece jugarlo en estos momentos y hasta su conquista Coria. Esta ciudad, pese a la poca información de que disponemos, creemos que articulaba toda una estructura defensiva completada con castillos ${ }^{12}$. No conocemos sus nombres, pues simplemente se alude a ellos genéricamente, pero es muy significativo que la conquista de Coria lleve encadenado el abandona del castillo de Albalat, situado estratégicamente en el Tajo y que haća mucho daño a los cristianos ${ }^{13}$.

Esta endeblez inicial viene ratificada por la escasa resistencia a las operaciones de Geraldo Sempavor, que con suma facilidad conquista las plazas extremeñas más importantes, excluida Badajoz, y ello debido a la intervención de Fernando II. Las fuentes nos ilustran suficientemente en sus rasgos generales la forma de actuar de este jefe portugués ${ }^{14}$. No estamos ante un ejercito organizado capaz de realizar asedios. Su actuación se basa en la sorpresa: en noches oscuras escala las murallas y tras eliminar a los guardianes ataca el lugar elegido. De este modo, realiza sucesivos golpes de mano que le permiten apoderarse de poblaciones tan importantes como Cáceres y Trujillo; además, a excepción de su alcazaba, llegará a controlar toda la ciudad Badajoz. No se trata de pequeños castillos sino de ciudades que poco después se convertirán en inexpugnables. Por tanto, estamos ante la calda sistemática de importantes fortalezas ante una persona que por las características de sus hombres no podemos definir sino como un aventure-

12 Fernando Il da Coria a la catedral de Santiago en 1162, "Totam et integram cum terminis suis castillis omnibus novissimus et antiquis cum regalibus omnibus" (A. LOPEZ FERREIRO, Historia de la santa apostólica metropolitana iglesia de Santiago de Compostela, IV, Santiago, 1901, doc. 32).

13 Tras la conquista de Coria, los habitantes de Albalat "magno timore perterreti sunt, et avertentes, reliquerunt castcllum vacuum" (Chron. Adeph. Imper., p. 126).

14 "El perro (Giraldo) caminaba en noches lluviosas y muy oscuras, de fuerte viento y nieve, hacia las ciudades y había preparado sus instrumentos de escalas de madera muy largos, que sobrepasasen el muro de la ciudad, aplicaba aquellas escaleras al costado de la torre y subía por ellas, en persona, hasta la torre y cogía al centinela y le decía: 'Grita como es tu costumbre', para que no le sintiese la gente. Cuando se había completado la subida de su miserable grupo a lo más alto del muro de la ciudad, gritaba en su lengua un gran alarido y entraba en la ciudad y combatían al que encontraban y lo robaban y cogían cautivos y prisioneros a todos los que estaban alli" (IBN SAHIB AL-SALA, Ibid., p. 137). 
ro. No cabe otra conclusión que la falta de estructuración de una zona de frontera, de una cuña que aparece rodeada al este y al oeste por tierras cristianas.

La fácil conquista de Cáceres por los almohades en 1174, cuando es clara su incapacidad en el asedio y conquista de ciudades ${ }^{15}$, es un síntoma evidente de todo lo que acabamos de decir.

Esta situación da un vuelco total después de 1174, cuando los almohades vuelven a situar la frontera en el Tajo (el señorío de Fernando Rodríguez el Castellano estaba bajo su dominio nominal).

Los almohades conscientes de la importancia estratégica de Extremadura y de su dificil defensa se afanarán en mejorar sus defensas hasta ponerlas a la altura de las necesidades ${ }^{16}$. Desde 1174 , la fortaleza defensiva de la Extremadura musulmana aumenta de modo claro. Se realizan numerosas obras. Las actuales murallas de Cáceres son prácticamente en su totalidad almohades; en su momento, junto a la muralla, conservada en muchos tramos, habra una barbacana o antemuralla ${ }^{17}$. En cuanto a Badajoz (en donde con anterioridad se hablan realizado importantes trabajos defensivos tras la expedición de Ordoño II en el 913 a la España musulmana), pese a los previsibles continuos arreglos, sus defensas no parecian estar acordes con la importancia de la plaza. La alcazaba, de una extensión similar al Cáceres musulmán, es, tal y como se conserva, una obra almohade mandada hacer por Abu Yaqub ${ }^{18}$. Reina y Montemolín, que protegfan ca-

is En la expedición de 1196, los almohades no consiguen apoderarse de ninguna plaza importante (A. HUICI MIRANDA, Las grandes batallas de la Reconquista durante las invasiones africanas (almorávides, almohades y benimerines), Madrid, 1956, p. 174).

${ }^{16}$ Como señala L. TORRES BALBAs, Ciudades hispanomusulınanas, Madrid, 1971, p. 482, "los monarcas almohades prestaron gran cuidado a la fortificación de sus ciudades extremeñas, situadas en una región de luchas continuas en la segunda mitad del siglo XII y en los primeros años del XIII, fronteriza con tres reinos cristianos -Castilla, León y Portugal- que trataban de dilatarse a costa del Islam. Extremadura era asimismo la comarca más septentrional y avanzada del dominio peninsular de los almohades y fácil puerta, una vez dominado el valle del Guadiana, para el paso al del bajo Guadalquivir. Ello explica que los restos más importantes de fortificaciones de este periodo se encuentren, aparte de Sevilla, en cuatro villas extremeñas, Cáceres, Badajoz, Reina y Montemolín".

"Hay una referencia a "torres y acitaras" en 1222 (Anales Toledanos, II, pag. 406 -en E. FLÓREZ, España Sagrada. Theatro Geographico-Historico de la Iglesia de España, XXIII, Madrid, 1767-).

18 Para los trabajos defensivos tras la expedición de Ordoño II, E. LEVI Provençal y E. GARCIA GOMEZ, Crónica anónima de 'Abd al-Raman III al-Nasir, Madrid-Granada, 1950, p. 112, e IBN HAYYAN DE CÓRDOBA, Crónica del califa 'Abderraman III an-Nasir entre los antos 912 y 942 (al-Muqtabis, V), Zaragoza, 1981 (traducc. de $M^{2}$ J. Viguera y F. Corriente), p. 
minos que se dirigian hacia el valle del Guadalquivir, se construyen en su totalidad también en este periodo. Es muy posible que otras fortificaciones extremeñas deban mucho igualmente en la forma en que se conservan a los almohades $^{19}$. En cualquier caso, los ejemplos citados son de por sí suficientemente importantes.

La política almohade dará sus frutos después de las Navas de Tolosa, cuando, en un momento de claro y definitivo predominio cristiano, las conquistas en el territorio extremeño sean algo realmente difícil. Esta nueva solidez se manifiesta en la necesidad de conquistar determinadas plazas ante de intentar el asalto a Badajoz, centro neurálgico del territorio extremeño. El desarrollo de las conquistas de Alfonso IX así lo muestran: no baja al valle del Guadiana hasta tanto no controla Cáceres y Alcántara. Quizás las consecuencias de la política almohade no aparezcan reflejadas en ningún sitio con tanta claridad como en la capital altoextremeña: sufrirá un asedio en 1184 y tres depués de Las Navas de Tolosa -1213, 1218 y 1222(el primero de los mismo incluso con una notable ayuda castellana). Todos resultaron infructuosos ante una ciudad que habia caído fácilmente ante Geraldo Sempavor. Estos asedios se realizaron con huestes reales y se usaron ingenios para la destrucción de las murallas ${ }^{20}$. Es normal que las fuentes cristianas se refieran a Cáceres como "castrum famossum" o como "muy fuerte castillo"21.

Cáceres no es un ejemplo aislado, pese a la parquedad de las fuentes. Otros castillos se convirtieron en "inexpugnabile", término con el que la Crónica de los reyes de Castilla designa al de Capilla, asediado por el mismo Fernando III en 1226; sólo pudo ser tomado por pacto ante la imposibilidad de recibir ayuda exterior, pero sus muros eran lo suficientemente

83. Sobre la alcazaba de Badajoz, cf. L. TORREs Balbás, La alcazaba almohade de Badajoz, "Al-Andalus", VI (1941); F. VALDÉs, La alcazaba de Badajoz. Hallazgos islámicos y testar de la Puerta del Pilar, Madrid, 1985, y Ciudadela y fortificación urbana: el caso de Badajoz, "Castrum", 3 (1988, Madrid).

19 Cf. nota 81. Asimismo, serían almohades gran parte sino la totalidad de las fortificaciones de la Siberia extremeña y la zona oriental de la Serena, como se expone en el presente estudio.

${ }^{20}$ En el asedio de 1213, Alfonso IX conto con "Diago Lop, e Lop Díaz con DC caballeros vien quisados en ayuda", tomando Alcántara pero fracasando frente a Cáceres (Anales Toledanos, I, pag. 398 -en Esparia Sagrada, XXIII-).; en 1222 hay referencia a la utilización en el asedio de "almajinequis" (Ibid., p. 406).

${ }^{21}$ Crónica latina de los reyes de Castilla, Cádiz, 1984 (edic. de L. CHARLO BREA), p. 78; y Lucas de Tuy, Crónica de España (edic. de J. PUYOL), Madrid, 1926, p. 423. 
consistentes como para resistir el asedio con "machinis mirificis"22. Quizás no habria que olvidar que las fuentes castellanas se refieren a Capilla en los términos señalados la primera vez que es mencionada. No era, posiblemente, por tanto, una plaza especialmente fuerte o excepcionalmente importante. Esto aún le da más valor. Cáceres y Capilla no son dos excepciones. Las fuentes cristianas aluden a otras plazas bien defendidas, como tendremos ocasión de ver.

De todo lo anterior merece la pena que retengamos algunas ideas fundamentales: 1) Extremadura parece estar defensivamente poco dotada para la situación que se crea tras la conquista definitiva de Coria por los cristianos; de todo esto parece derivarse que esta ciudad junto con una serie de castillos situados entre el Tajo y el Sistema Central (se trata en realidad de una hipótesis pues al margen de aspectos concretos sólo tenemos sobre el particular una mención genérica) tendría un papel defensivo muy importante; 2) los almohades conscientes de la importancia geoestratégica de Extremadura y de su condición de cuña musulmana rodeada de tierras cristianas desarrollaron una labor importante de construcciones defensivas que sólo un estudio atento de los restos materiales nos permitiría valorar correctamente, pero que en todo caso las fuentes escritas nos autorizan a considerar como muy importante; 3) la política almohade es un éxito al dotar a Extremadura de numerosos puntos defendidos muy fuertemente que demostrarán su solidez sobre todo entre Las Navas de Tolosa y la definitiva conquista cristiana.

\section{LA ESTRUCTURA DEFENSIVA}

La estructura defensiva de la frontera extremeña o de cualquier otra tiene un claro carácter jerárquico. Es concebida como un todo en el que cada parte cumple una función especifica y distinta a la de otras de rango diferente. Una consecuencia de esta realidad es la existencia de diversos términos para designar a los centros fortificados. Sin embargo, tanto el vocabulario cristiano como el árabe, que deberían ser un elemento central para abordar el estudio tanto del hábitat como de la organización defensiva,

\footnotetext{
22 Crónica latina de los reyes de Castilla, p. 71; la misma fuente también se refiere al castillo como "castrum nobile, fortissimum et famosum" (Ibid.).
} 
se caracterizan por su imprecision y polisemia. En el caso cristiano, algunos términos son, en realidad, más adjetivos que sustantivos.

En teoría, la situación es clara. Los musulmanes llaman madina a un centro de habitat importante en un sentido demográfico. Es el equivalente de lo que denominamos ciudad. Tanto como un centro fortificado es, y en mayor medida, un importante núcleo poblacional. El qal'a vendrfa a ser una gran fortaleza que no llega al nivel de la medina y se distingue del hisn, que viene a ser el equivalente del simple castillo y cuya población está compuesta exclusiva o fundamentalmente por personas de dedicación militar, en sus dimensiones.

Los cristianos reservan la denominación de civitas, que reservan para ciudades de gran importancia que cuenta con importantes funciones, como la episcopal. Más frecuentes son los términos villa o castro-castillo-oppidum. En realidad, los citados en segundo término nos informan de poco más que del carácter amurallado del núcleo habitado. El primero no es mucho más explícito y sólo alude a la existencia de personas no ligadas directamente a la defensa que generalmente vivían fuera de las murallas. La utilización de uno y/u otro término nos será de utilidad.

Dada la escasa utilización de madina y civitas, y la práctica inexistencia de qal'a en Extremadura ${ }^{23}$, hisn y castro-castillo ${ }^{24}$ son omnipresentes. Muchas fortalezas extremeñas, pese a sus muy variadas características en cuanto a extensión y población, reciben ambas denominaciones. Por ello, el término con que se les designa no es significativo, $0_{\text {a }}$ lo es en una mínima medida.

En algún caso, se utiliza más de un término para designar a una misma población. Así sucede con Cáceres que aparece como hisn y como madina $^{25}$. Igualmente Alange, único caso mencionado en fecha temprana

${ }^{23}$ Sólo hemos encontrado una mención: Ibn Hayyan denomina de este modo al castillo de Alange (Fuentes, I, 249). Este castillo no es especialmente grande y no parece adecuarse a la definición de E. Levi Provençal, que presenta a los qal'a como "verdaderas plazas fuertes que por lo común dominaban la llanura fértil y populosa que se trataba de proteger" (Espanta musulmana. Hasta la caida del califato de Córdoba (711-1031). Instituciones y vida social e intelectual, Madrid, 1965 -tomo 5 de la Historia de España dirig. por R. MENENDEZ PIDAL-, p. 34).

${ }^{24}$ Oppidum aparece como un termino enudito; sólo se utiliza para Alburquerque en 1171, en el acuerdo entre la orden y la catedral de Santiago (M. R. MARTINEZ Y MARTINEZ, Ibid., p. 341), Merida -oppidi panvi- (Crónica latina de los reyes de Castilla, p. 79) y Alcántara (Alfonso IX, II, doc. 347).

${ }^{25}$ Fuentes, pp. 400 y 402 ; IBN SAHIB AL-SALA, lbid., p. 138). 
como qal'a, aparece también citado por al-Idrisi como hisn ${ }^{26}$. Distinto es el caso de Badajoz, pues el cambio de denominación se debe a la absoluta transformación que sufre desde su ocupación inicial cuando era una simple fortificación, hasta su conversión en el centro de la Extremadura musulmana.

En cualquier caso, el vocabulario cristiano, sobre todo, y árabe son suficientemente imprecisos como para que no puedan ser utilizados para realizar una adecuada clasificación de los centros de hábitat. Pueden designar realidades demasiado diferentes ${ }^{27}$, cuando no nos informan simplemente de determinadas características. Los restos materiales (murallas, torres, etc.) son mucho más valiosos para hacernos una idea de la importancia que tendrían los diversos centros de hábitat.

En Extremadura, la defensa, como en cualquier otra zona, se estructura con lugares de desigual importancia demográfica y, por tanto, defensiva. La ubicación concreta estará en función del peso poblacional de cada punto. A mayor población más factible es la defensa en un lugar sin especiales defensas naturales. Cuando, como sucede con los típicos castillos, cuentan con un contigente demográfico limitado, la ubicación en lugares escarpados de dificil acceso es imprescindible e ineludible: ningún castillo es defendible en un llano. Además, los centros con bastante población unen a su finalidad defensiva una economica, con lo que es imposible su asentamiento en lugares escarpados, inutiles para la agricultura y el comercio. Se trata ademas lugares que en muchos casos son antiguos y que en estos momentos cuentan con siglos, o milenios, de existencia. Esto no significa que en la ubicación de estos centros no se tengan en cuenta determinadas circunstancias. Badajoz se sitúa al sur del Guadiana y la alcazaba aprovecha una gran pendiente del lado del río. Esto hacía que la ciudad sólo pudiera atacarse por el sur. También un río era aprovechado por Alcántara, pero en este caso es el Tajo, que constitura, dada la escasez de vados, una auténtica muralla natural en esta epoca. Esto hacía que Alcántara fuera inexpugnable por el norte, lo que reducía los lados por los que

\footnotetext{
${ }^{26}$ AL-IDRISI, Los caminos de al-Andalus en el siglo XII, Madrid, 1989 (edic. de J. ABID MizAL), pag. 82 (M* A. Pérez AlvAREZ, Fuentes, I, 129, ha dejado el término árabe en su traducción).

27 Esto ha obligado, por ejemplo, a A. BAZZANA, P. CREsier y P. GUICHARD, Les chateaux rurales de al-Andalus. Histoire et archeologie des husun du sud-est de l'Espagme, Madrid, 1988, p. 107, a realizar una clasificación de los castillos árabes que no tiene en cuenta la terninología de la fuentes.
} 
podra ser atacada. También Trujillo y Cáceres dependran de su población y de sus defensas para resistir ante el avance cristiano. Ambas poblaciones contaban con su alcazar, situada en la parte más elevada de la ciudad. Sin embargo, sobre todo la primera, estaban situadas en una llarura. Esto no disminuirá su poder defensivo $\mathrm{y}$, de hecho, acabarán constituyéndose como las dos llaves defensivas de la Extremadura musulmana. Ya hemos aludido a la gran labor almohade para hacer de Cáceres una plaza muy bien defendida. En cuanto a Trujillo, lo imponente de sus murallas y de su castillo, conservados en general en muy buen estado en la actualidad, son suficientemente claros sobre la fortaleza de sus defensas. En ambos casos influye en su ubicación exacta su origen romano, pero su importancia en el periodo final de la España musulmana se debe a que el centro defensivo de espacios amplios no son los castillos, sino las ciudades. Dentro de esta categoría podemos incluir también a Mérida y Medell ín. No son simples castillos, sino que cuentan con una población relativamente importante comparada con éstos, pero su importancia es muy inferior a las ciudades citadas con anterioridad. Se ubican en una fértil llanura, la del valle del Guadiana, y al igual que Cáceres o Trujillo tienen un origen romano.

Los castillos tienen una funcionalidad distinta; salvo excepción (defensa de una vía muy importante, etc.) su importancia no trasciende lo comarcal. Su escaso peso demográfico hace necesario su ubicación en un lugar de fácil defensa, cuando no de muy diffcil acceso incluso para los defensores. Generalmente están situados en lugares muy defendidos por el relieve. Al Bakri decfa del de Santa Cruz que está "tan elevado que no llegan allı ni el águila ni otras aves"28; no en peores condiciones está el de Alange, al que sólo se llega después de más de una hora de camino. El de Monfragüe esta situado en la sierra de las Corchuelas cerca de la confluencia del Tajo y el Tietar. También el de Benquerencia es de difícil ataque por su gran pendiente. En otros casos, aprovechan afloramientos rocosos aunque estén situados en medio de tierras relativamente llanas. Es el caso de Alburquerque o Almorchón. Otros castillos están menos protegidos por el relieve sin dejar de estar en buena posición, como Reina, Montemolín o

${ }^{28}$ Fuentes, I, 109. 
Montánchez ${ }^{29}$. Protegiendo importantes vías de penetración, los castillos compensan su escaso contigente humano con su aliado natural, el relieve.

Algunos castillos se asientan en lugares de más difícil defensa ante la necesidad de proteger algún punto de importancia. Así, el de Albalat cuenta con la protección del Tajo, pero en su retaguardia tiene como único aliado la llanura. El de Lobón cuenta con una escarpada pendiente del lado del Guadiana, pero el paso del mismo no es difícil y es de fácil ataque por el sur. De todos modos, se sitúa en la retaguardia. En estos casos, la necesidad de proteger vías de paso (Albalat significa exactamente el camino y tiene una cierta importancia en las vias musulmanas ${ }^{30}$ ), condiciona la ubicación exacta. En cualquier caso, Albalat no resistió tras la conquista de Coria: se apoderó un gran temor de sus habitantes, conscientes de que no podían fácilmente resistir en primera línea de frontera y abandonaron el lugar. Contrasta esto con el protagonismo de sus habitantes con anterioridad y con, por ejemplo, el comportamiento de Alcantara, población de más entidad.

Estos castillos oscilan entre una función exclusivamente defensiva y otra más amplia derivada de la existencia de una población que ejerce diversas actividades económicas (las fuentes cristianas hablarán entonces de la villa). La arqueología puede ser de mucha utilidad para permitir una clasificación de las defensas musulmanas. Las fuentes cristianas, sin embargo, vienen en nuestra ayuda y nos permiten algunas matizaciones. Montanchez aparece como "castrum et villam". La mayor parte de los castillos importantes se presentan de este modo. Asl sucede con Albalat (destruido muy pronto por los cristianos), Alcántara, Benquerencia, Magacela, Reina o Zalamea ${ }^{31}$. No está claro que también fuese villa el importante castillo de

\footnotetext{
${ }^{29}$ IBN IDARI, en relación con la ofensiva almohade de 1196, decía de él que "era una de las fortalezas de mayor elevación, renombrada por lo abrupto y fortificado" (A. HUICI Miranda, Colección de crónicas árabes de la reconquista, Tetuán, II, 1953, p. 193).

30 Albalat estaba comunicada, según al-Idrisi, con Alcántara, Talavera y Calatrava (Caminos, p. 84).

${ }^{31}$ Alfonso VIII, III, doc. 641; Alfonso XX, II, docs. 346 y 620; Femando III, III, doc. 521, 680 y 739; M. R. MARTINEZ Y MARTINEZ, Ibid., pp. 425-426 (este detalle suele concretarse casi siempre en los documentos de donación de los diversos lugares).
} 
Capilla o el de Montemolín ${ }^{32}$. No se alude en las fuentes ni quedan restos arqueologicos que permitan pensar en la existencia en estos castillos de un muro exterior o albacar que sirviese de refugio a los pobladores de las villas: en cualquier caso, solo se contaba con un recinto único, el que propiamente formaba el castro. En otros muchos casos, solo hay referencia al carácter defensivo de estas construcciones y no a ninguna población con otras funciones. Asi, sucede con Alange, Alcocer, Santa Cruz o Almorchón;la ubicación de algunos de estos castillos en lugares a veces casi inaccesibles haría difícil la existencia junto al castillo de una villa.

Dentro de los castillos hay un grupo que tendría muy escasa importancia. Son aquellos que no merecen en las crónicas o en los documentos mención alguna, consecuencia de su papel muy secundario en la estructuración de la defensa del territorio. Sólo son mencionados de pasada en delimitaciones de términos u otros tipos de documentos en los primeros momentos de época cristiana. Son castillos como los de Tamuja, Cogolludo, Mayorga, Piedrabuena, Al-Sajra (Peña) -cuyo nombre nos muestra sus características de ubicación y su poca importancia ${ }^{33}$, Valera o Sigonsa. La existencia de todos ellos en época musulmana no es absolutamente segura, pero su pronta aparición en las fuentes cristianas parece abogar por esta posibilidad. Su papel en la defensa seria secundaria y claramente en colaboración con otros puntos defensivos de mayor importancia.

La estructura defensiva se completa con las torres y atalayas. Estas aparecen en la documentación muy escasamente, pues no son estructuras preparadas para resistir y que preocupen al invasor. Las primeras cumplirían la función de dar un resguardo de urgencia a los habitantes de las alquerfas. Ninguna serfa capaz de aguantar un asedio serio. La alquería de Besnageth, cerca de Montemolín, es concedida por Fernando III en 1248 "con su torre et con sus terminos e con sus pertenencias, assi como los

32 Fermando III da en 1236 al Temple el "castrum" de Capilla (J. GONZALEZ, Fernando III, III, doc. 575); sin embargo, los Anales Compostelanos crean alguna duda al respecto, cuando hablan de que "Capta fuit Ubeda, et Martos cum allis circunstantibus Castris et villis, Baeza, et Capiella, et San Estevan, Andujar, et Aznatoraz, et Quesada, Xodar et allis" (en "España Sagrada", XXIII, pag. 324). En cuanto a Montemolín, aunque aparece alguna vez como "castri", en el documento de donación del lugar no se especifica nada sobre el particular (A. F. AGUADO DE CORDOBA, Ibid, doc. 2, pp. 174-175; J. GONZÁleZ, Femando III, III, doc. 763).

${ }^{33}$ El nombre de este castillo es significativo: E. LEVI PROVENÇAL, España musulmana, p. 37, define al sajra como un castillo más pequeño que el hisn, "una especie de 'recintos naturales', apenas modificados y casi inaccesibles". 
mejor ovo en tiempo de moros". Poco después de la ocupación cristiana, en 1255, Alfonso X concede a la Orden de Alcántara Calamonte y Gevora con sus correspondientes torres. En una donación en 1288 a la Orden de Alcántara aparece la torre de Fenojares, pero quizás no fuese de época musulmana ${ }^{34}$. Junto a estas torres de alquerías, situadas en la retaguardía extremeña, al sur de las sierras de San Pedro y Guadalupe, en la delimitación de Cáceres, que aparece en el fuero, se citan diversas torres . ¿Son torres de alquería o más bien atalayas? En un caso se habla de Montanchez de la Torrecilla, lo que parece indicar que está unido a un centro de poblamiento. En los demás casos simplemente aparece mencionado el nombre de la torre, a saber, de Blasco o Velasco Muza, de la Zafra y de la Greda ${ }^{35}$. En Trujillo, en 1257 aparece citada en una donación al obispo de Plasencia la torre del Almacen, situada en la vía Plasencia-Trujillo ${ }^{36}$. No son abundantes los datos con que contamos sobre el particular, pero no debemos olvidar que las alquerías aparecen sólo incidentalmente al no ser centros de defensa que causen gran interés a los conquistadores cristianos, a lo que se une que los musulmanes sólo mencionan los más importantes, dado el carácter muy selectivo de la información de sus fuentes sus fuentes. En cualquier caso, podemos afirmar la existencia posiblemente muy generalizada de torres que defienden las alquerśas, que quizás completasen su dotación defensiva con otros elementos ${ }^{37}$. Las mismas parecen abundantes entre el Tajo y la estribaciones extremeñas de los montes de Toledo (precisamente la zona en que es menos seguro que estuvieran unidas a alquerfas y no fueran una especie de atalayas) y contribuirían a consolidar la defensa en este sector, el más directamente expuesto a los ataques cristianos.

Gran importancia tienen las atalayas, en cuanto que dada su ubicación, en puntos de fácil visibilidad y comunicación entre ellas, permiten el

\footnotetext{
34 J. GONZALEZ, Fernando III, III, doc. 763; I. J. ORTEGA Y COTES, Bullarium ordinis militiae de Alcantara, Madrid, 1759, docs. 14, p. 89, y 13, p. 121.

${ }^{35}$ P. LUMBreras, Los fueros municipales de Cáceres. Su derecho püblico, Cáceres, 1974, p. IX.

36 D. SÁNCHEZ LORO, Historia Placentinas inéditas, vol. A, Cáceres, 1982, p. 399.

37 A. BAZZANA y P. GUICHARD, Les tours de defense de la huerta de Valencia au XIIIle siècle, "Melanges de la Casa de Velázquez". XIV (1978), pp. 96-97, sostienen como hecho general una triple composición de las defensas de las alquerias valencianas en el momento de la conquista: una empalizada poco consistente que la rodearía, un albacar alrededor de la torre que senviria de refugio y la torre propiamente dicha, con capacidad para resistir un asedio de varios días.
} 
conocimiento de las operaciones y movimientos enemigos. Al igual que las alquerfas, su aparición en las fuentes es escasa y secundaria. Sin embargo, aparecen en muchos casos en las delimitaciones de términos. En el de Cáceres se mencionan dos atalayas (Atalaya "Davencalez" y Atalaya del Guijo de la Sierra) a unir a las torres ya citadas ${ }^{38}$. En la carta de confirmación de los límites de Badajoz expedida por Alfonso X se alude a la atalaya morisca y a la del Ceriagal, aunque abundan más los castillos ${ }^{39}$. En los límites de Mérida aparecen la atalaya de Pelayo Remelado y la del Naharro ${ }^{40}$. No contamos con los límites de Trujillo, que nos serfan de gran interés, pero todo hace pensar que estas defensas de menor envergadura y de tanta importancia quizás fuesen más numerosas entre el Tajo y las estribaciones extremeñas de los Montes de Toledo (no debemos olvidar lo señalado para las torres) que más al sur. Su mayor carácter fronterizo explicaría esta situación.

La Extremadura musulmana cuenta con una jerarquizada estructura defensiva que va desde la importante ciudad de Badajoz, una de las mayores de la España musulmana en estos momentos ${ }^{41}$, hasta la torres y atalayas. Ciudades de menor importancia y sólidas defensas como Cáceres y Trujillo y castillos estratégicamente situados completan el conjunto defensivo dotándole de la solidez que hemos visto. Esta solidez hace posible que ni Fernando II ni Alfonso IX puedan plantearse la conquista de Badajoz, que descabezaría toda la Extremadura musulmana hasta tanto no hayan conquistado Cáceres.

Espacialmente, la estructura defensiva extremeña conoce 3 claras zonas: la que se extiende entre el Tajo y las estribaciones extremeñas de los Montes de Toledo; el valle del Guadiana, que incluye los pasos a través de Sierra Morena a Andalucia y la zona oriental de la actual provincia pacense. Dos de ellas, la primera y la última,limitan con tierras cristianas, mien-

\footnotetext{
33 P. LUMBRERAS, Ibid., p. IX.

39 E. RODRJGUEZ AMAYA, La tierra en Badajoz (1230-1500), "Revista de Estudios Extremeños", VII (1951), p. 12.

$40 \mathrm{~J}$. GonzÁlez, Alfonso IX, II, doc. 600.

${ }^{41}$ L. Torres Balbas conjugando diversos datos sobre extensión de una vivienda media y número de habitantes por vivienda ha realizado algunas estimaciones de población en la España musulmana. Así, en la segunda mitad del siglo XI y en el XII, Badajoz contaria con veintiseis mil habitantes, más que Malaga, Valencia, Zaragoza o Mallorca, igual que Granada y sólo menos que Toledo y Sevilla (Ciudades hispanomusulmanas, p. 106).
} 
tras la segunda podemos considerarla en un sentido relativo como retaguardia.

Dentro de la primera zona, aparecen tres niveles defensivos con nitidez: el Tajo, la penillanura trujillano-cacereña que se extiende al sur y los montes que dividen las cuenca del Tajo y el Guadiana. En el primero y último nivel hay castillos o, en terminología árabe hisn. Sólo Alcántara tiene un peso demográfico claramente superior a los demás. El segundo nivel cuenta con dos auténticas llaves defensivas, Cáceres y Trujillo.

El Tajo se constituye como una barrera natural dado el encajonamiento del río y la escasez de pasos. Estos están jalonados de defensas. Los musulmanes cuentan con diferentes punto fortificados sobre el rfo: Alcántara, Monfragüe y Albalat. La importancia de estos centros fortificados es muy desigual. Monfragüe es un pequeño castillo situado en la sierra de las Corchuelas y muy próximo a la confluencia del Tajo y el Tiétar. No alcanza los quinientos metros cuadrados y el número de defensores que podía tener es limitado. Posiblemente, sólo tuviera una función defensiva. Cuando Alfonso VIII en 1189 lo da a Plasencia como aldea esta pensando más en el poblamiento futuro que en la existencia de un nucleo de población ${ }^{42}$. Es significativo que este castillo no dé origen a una villa sino que se integre en un alfoz mayor. Distinto es el caso de Albalat. Aparece no como castillo sino como villa y castillo. Esta fortificacion es de dimensiones muy superiores a la anterior, pues tiene una superficie de varios miles de metros cuadrados. No parece que la villa estuviera dentro de la misma (aunque hay un muro, quizás de época musulmana que divide el castillo en dos), en cuyo caso no contarfa con defensas especificas y el castillo sería un refugio. La importancia de Albalat (significa precisamente la carrera o el camino) deriva de su papel en las comunicaciones y como consecuencia de ello de su gran papel estratégico ${ }^{43}$. Al-Idrisi señala las distancias entre Albalat y Alcantara, Talavera, Calatrava y Miknasa ${ }^{44}$. Sus comunicaciones se extendran al este, al oeste y al sur y tenía una importancia en las comunicaciones equiparable a la de Alcántara.

\footnotetext{
42 J. GONZÁlez, Alfonso VIII, II, doc. 520.

${ }^{43}$ J. GonZÁleZ, Repoblación de Castilla la Nueva, I, Madrid, 1975, p. 144, afirma que Albalat era una base "análoga en poder ofensivo a la de Oreja" y "afectaba vivamente al sector de Talavera y a los concejos de Avila y Salamanca".

4 AL-IDRISI, Los caininos, p. 84.
} 
La importancia que tienen Albalat y Monfragüe en la estructura defensiva es muy inferior a la de Alcántara. Albalat, como hemos visto, es destruido tras el hundimiento almorávide por los concejos de Avila y Salamanca, a los que producía mucho daño. Monfragüe pasa a formar parte del señorfo de Fernando Rodríguez el Castellano. Ambos castillos aparecen en 1189 en relación con la política de defensa desarrollada en la zona por Alfonso VIII, que se hundirá pocos años después, en 1196. Tras esto, no se les vuelve a mencionar ni por parte de los musulmanes ni de los cristianos. Su conquista no aparece registrada. Es evidente que esto es debido en parte a que la política castellana tiene su centro más al este, en los castillos que jalonan el camino entre Córdoba y Toledo. La expansión castellana por la zona oriental extremeña sólo se realizará un par de décadas después de la derrota almohade de Las Navas de Tolosa. Lógicamente esto reduce el protagonismo de estas fortificaciones que creemos que estarian en poder musulmán, si no estaban destruidas. Monfragüe es donado en 1246 por Fernando III al concejo de Plasencia como castillo ${ }^{45}$. No aparece en la documentación de este rey Albalat: es posible que hubiese iniciado ya el camino de su despoblación.

Alcántara ofrece unas características diferentes. Estamos ante un centro con alcázar que dispone de una muralla que rodea la villa hoy no mantiene el trazado de época musulmana, pues la superficie fortificada aumento considerablemente en el siglo $\mathrm{XVII}^{46}$ ). Alcántara aparece en las fuentes árabes como una plaza sólidamente defendida ${ }^{47}$. Su mayor peso poblacional (en lo que supera con absoluta claridad a Albalat y Monfragüe) y su ubicación aprovechando la elevación del relieve (clara ventaja sobre Albalat, que sólo cuenta con la protección del Tajo) hace de Alcántara la más sólida defensa musulmana sobre el Tajo. Precisamente por ello, Fernando II incluirá entre sus cláusulas cronologicas la conquista de esta villa en 1166 (la conservará hasta el ataque almohade de 1174$)^{48}$. La importan-

45 J. GONZAIEZ, FERNANDO III, III, doc. 742.

46 Jacinto ARIAS QUINTANADUEÑAS, Antigüedad y Santos de la muy noble villa de Alcántara, Madrid, 1669, 21 y s8 (citado por A. NAVAREÑO MATEOS, Arquitectura militar de la orden de Alcántara en Extremadura, Salamanca, 1987, p. 106).

47 A. UBIETO ARTETA, Descripción de España de Idrisi, Valencia, 1974 (en adelante citaremos AL-IDRISI, Geografia), pag.172, dice que "La población habita en esta fortaleza, donde está al abrigo de todo peligro, porque sólo se la puede atacar por el lado de la puerta".

48 Así sucede en los documentos emitidos por la cancillería de este rey entre Enero y principios de Febrero (J. GONZALEZ, Femando II, pp. 393-394). 
cia de Alcántara se cimenta en su papel en las comunicaciones de la España musulmana. Aparece comunicada con Mérida, Badajoz y Albalat ${ }^{49}$ y en su momento el camino Badajoz-Coria no debería pasar muy lejos de la villa si no la cruzaba. Bien defendida, el relativo predominio militar de los almohades hasta Las Navas de Tolosa y el escaso belicismo de los reyes leoneses en este periodo posibilita una relativa tranquilidad para esta población. En cualquier caso, en 1184, año del asedio de Cáceres por Fernando II, no hubo intentos de conquista de Alcántara. Posiblemente, el rey leonés utilizó el paso de Alconétar y se dirigió a Cáceres al considerarla la plaza clave de las que se extendian entre el Tajo y las sierras de San Pedro y Montánchez. La decidida política castellana que sigue a Las Navas propicio la definitiva conquista de Alcántara en 1213, en una campaña donde la finalidad esencial era Cáceres. El asedio de la villa no parece que fuera demasiado largo, pues dio tiempo a que se intentase la conquista de esta ciudad. En cualquier caso, las circunstancias de la conquista de Alcántara muestran como sólo pocas poblaciones son capaces de resistir asedios en toda regla ${ }^{50}$ y Alcántara no parece que fuera una de ellas.

Detrás de la línea del Tajo se instala otra más sólida, la que forman Cáceres y Trujillo. Es precisamente la fortaleza defensiva de estos dos lu- gares lo que permite que con sus matizaciones este rfo se convierta en gran parte de la zona extremeña en una frontera. La información sobre las dos fortalezas es desigual, debido a que estaban dentro de la zona de expansión de dos reinos peninsulares diferentes. León intentará extenderse a la largo del occidente extremeño, su única zona posible. Castilla, con una línea fronteriza muy superior, considera prioritario avanzar a la largo de las fortalezas que jalonan el camino Toledo-Córdoba, donde precisamente se da la batalla de Las Navas. Alfonso VIII se mostró muy interesado en la zona trujillana cuando recibió la herencia de el Castellano por medio del hijo de éste, pero una vez que pierda sus bases al sur del Tajo no intentará ninguna expedición sobre ellas en el resto de su reinado, que se dilata aún casi dos decenios. Trujillo, por tanto, no es considerado vital por los castellanos, que piensan en esta ciudad como una retaguardia a conquistar cuando las

49 AL-IDRISI, Los caminos, p. 84 (la comunicación con Mérida y Badajoz aparece ya citada por Ibn Hawqal).

${ }^{50}$ En la campaña de Las Navas, en la que no se utilizaron maquinas de asedio, "ninguna fortaleza, ni la misma de Calatrava, resistió un asalto de más de veinticuatro horas" (A. HUICI MIRANDA, Las grandes batallas de la Reconquista, p. 293). 
arterias vitales de los musulmanes estén ya bajo el control cristiano. Nos debemos olvidar que Trujillo no es conquistado por las armas por Alfonso VIII, que se limita a recoger una herencia en sI misma ilegítima, pues Fernando Rodríguez el Castellano tenía simplemente la tenencia de diversas fortalezas extremeñas en tanto servidor de los almohades.

Trujillo y Cáceres corren, por tanto, una suerte y un protagonismo muy desiguales. Trujillo aparece como una ciudad sólidamente defendija que no necesitará poner a prueba esta característica. Cáceres pasa a ser una ciudad de vital importancia para el reino leonés, por lo que se la someterá a sucesivos asedios. Estos se darán fundamentalmente después de Las Navas, pero ya Fernando II intentó una segunda conquista de la ciudad. Desde la última década del XII hasta la segunda del XIII hay para las dos poblaciones una relativa tranquilidad, debido al predominio almohade.

Tanto Cáceres como Trujillo tienen una población muy superior a la de los demás centros defensivos de su zona. Si admitimos los calculos de L. Torres Balbas, las murallas cacereñas podrían albergar en circunstancias normales unas dos mil ochocientas personas ${ }^{51}$. La población de Trujillo no debla ser inferior, sino en todo caso superior. Al contrario que Cáceres, siempre aparece como ciudad ${ }^{52}$. Ambas población tienen una función que trasciende la meramente defensiva, convirtiéndose en centros económicos, especialmente Trujillo, de importancia al menos comarcal. Esto explica su ubicación en espacios relativamente llanos, aunque la alcazaba trujillana aprovecha una elevación. También el alcázar de Cáceres, hoy desaparecido, se situaba en la parte más elevada de su ciudad monumental, que cuenta con una pendiente limitada. Estos dos centros, por su peso demográfico, su actividad económica y su papel estratégico eran necesarios para estructurar y dar solidez a la primera línea de frontera.

Cáceres y Trujillo estaban muy sólidamente fortificados, como atestiguan los restos materiales. La Cronica latina de los reyes de Castilla llama

S1 L. TORRES BALBAS, Ciudades hispanomusulmanas, p. 102, calcula una población de 348 personas por hectárea. Es exagerada la estimación de C. CALLEJO, Los origenes de Cáceres, Cáceres, 1980, pag. 114, que considera que Cáceres podía albergar entre sus murallas diez mil guerreros. En cualquier caso, dada el protagonismo y la importancia estratégica de Cáceres, su población real pudo ser superior a la que hemos estimado como normal.

52 AL-IDRISI, Geografia, p. 177, la considera el centro comercial más importante en la zona que analizamos. Indistintamente, Trujillo aparece como ciudad en autores próximos cronológicamente al periodo que estudiamos, como Ibn Said, Ibn Idari, al-Idrisi o Yaqut. 
a la capital altoextremeña "castrum famossum" y Lucas de Tuy se refiere a ella como "muy fuerte castillo" 33 . La solidez de sus defensas queda demostrada en la tenaz resistencia que ofrece a los sucesivos asedios en un momento en que importantes plazas andaluzas mucho más populosas se entregan sin demasiados problemas a los castellanos. El de 1184 , realizado por Fernando II, se debió prolongar a la largo de varios meses: el 19 de Enero y el 8 de Junio, este rey concede documentos en Ciudad Rodrigo; no es excesivo pensar que una parte importante de la primavera debio estar ante los muros de Cáceres ${ }^{54}$. Merece la pena que nos detengamos en los asedios de Alfonso IX, realizados en 1213, 1218, 1222 y 1229 (el último y definitivo). En 1213 contó con un aporte de caballeros castellanos al frente de los cuales estaban los Haro. La cifra que dan las fuentes, seiscientos, posiblemente es excesiva; los Anales Toledanos se limitan lacónicamente a decir "non la poderon prender"ss. La información sobre el asedio de 1218 es más amplio y nos muestra que estamos ante una de las plazas consideradas centrales por los cristianos. Lucas de Tuy nos habla de una "gran hueste", pero los Anales Toledanos son más precisos: "Ficieron cruzada los freyres de las ordenes de España con las gientes del rey de Castiella, e del rey de León, de los otros regnos quantos quisieron venir y, e Savaric de Mallen con muchas fientes de Cascoña, e fueron cercar Cancies". Al igual que en 1213 estamos ante una hueste leonesa con considerables refuerzos ajenos. El rey leonés no pierde posibilidad de encontrar colaboración foránea para atacar esta plaza, lo que contrasta con prácticamente todos los asedios de las demás ciudades. En este ocasión, la climatologla (el asedio se extendió de mediados de noviembre hasta casi Navidad) jugó un papel adverso debido a la abundante lluvia (quizás no fuera más que una excu$\mathrm{sa})^{56}$. Nuevamente en 1222 el rey leonés se puso frente a los mismos muros y de nuevo hay una importante colaboración peninsular ("e fueron y todos los freyres de España, e grandes fientes de España"), se utilizan ingenios para abrir huecos en las murallas ("almajeniques") e incluso se obtuvieron éxitos ante las fuertes murallas cacereñas ("e derrivaron torres e acitaras"). Aún ası́, la conquista no debió parecer fácil a Alfonso IX (pese

\footnotetext{
${ }^{33}$ LUCAS DE TUY, Ibid., p. 423; Crónica latina de los reyes de Castilla, p. 78.

s4 J. GONZALEZ, Femando II, docs. 50, 51 y 52, y pp. 494 y 495.

ss Anales Toledanos, I, p. 398.

${ }^{36}$ LUCAS DE TUY, Ibid., p. 422; Anales Toledanos, I, p. 400.
} 
a la opinión del cronista de que "estaban en hora de la prender") cuando estuvo presto a aceptar una compensación económiça del rey marroqui para que descercase la villa ${ }^{57}$. La conquista definitiva se realiza con la colaboración de Fernando III, hijo del rey leonés y a la sazón rey castellano desde $1217^{58}$. Alfonso IX no realiza ningún intento de conquista al sur de Cáceres antes de la toma de esta ciudad, a la que considera la llave defensiva de la Extremadura que van a conquistar los leoneses. En este sentido, Cáceres es la llave del Guadiana (también pudo serlo Trujillo, pero ya hemos vistu como la política castellana tenía otras prioridades) y a su vez del Tajo, pues su conquista hacia indefendible cualquier punto situado más al norte ${ }^{59}$. La fortaleza de sus defensas (contaba con una barbacana, en la actualidad totalmente desaparecida, que las harra imponentes) era suficiente como para aguantar sucesivos asedios de ejércitos muy numerosos y aguerridos aunque sólo fuese porque para una parte importante no estaba en juego la expansión de un reino (León) sino el botín, sólo accesible con la conquista. La dificultad de la toma de Cáceres contrasta con la facilitad relativa con la que realiza sus conquistas posteriores Alfonso IX (Mérida y Badajoz caen en poco tiempo). Esto significa que los almohades también consideraban a Cáceres una auténtica llave y no debieron escatimar recursos para sus murallas y para mantener all guarniciones nutridas. Aún sin éstas, la población cacereña autóctona podrfa contar con cerca del millar de combatientes, que para labores estrictamente defensivas es una cantidad elevada ${ }^{60}$.

Cáceres debe su desarrollo en este momento a su excepcional importancia defensiva. Su papel en las vías de comunicación en la España musulmana era muy limitado. Al-Idrisi e Ibn Hawqal (siglo X) recogen las distancias respecto de Trujillo y Miknasa, ciudad desaparecida con anterioridad al siglo XII ${ }^{61}$. En ambos casos, Cáceres era punto final de destino y no de tránsito. Desde Ibn Hawqal hasta mediados del siglo XII no vuelve a aparecer Cáceres en las fuentes árabes. Todo hace pensar que era una po-

57 Anales Toledanos, II, p. 406.

SB LUCAS DE TUY, Ibid., p. 423.

${ }^{39}$ Lo mismo opina C. CALleso Serrano, lbid.,' p. 114.

${ }^{60}$ Cuando en 1410 se conquista Antequera su número de habitantes estimado era de dos mil quinientos veintiocho, de los cuales ochocientos noventa y cinco eran combatientes ( $L$. TORRES BALBAS, Ciudades hispanomusulmanas, p. 102).

${ }^{61}$ AL-IDRISI, Los caininos, p. 84; IBN HAWQAL, Configuración del mundo fragmensos alusivos al Magreb y Espana). Trad. de M. I. Romani Suay, Valencia, 1971, p. 68. 
blación geográficamente marginal, que desempeñaba un papel muy modesto en las vías de comunicación de la España musulmana (no aparece directamente relacionada con Badajoz, Mérida, Alcántara, Coria o Albalat) y que por tanto tenía una pequeña entidad. Su ubicación la dotará de un gran protagonismo en la defensa fronteriza de la segunda mitad del XII y primer tercio del XIII. Esto propiciará el desarrollo de Cáceres no sólo como plaza defensiva sino posiblemente también como centro de actividades económicas; esto hace que aparezca a veces como ciudad. Aunque la presenta como tal Ibn Idari antes de la conquista de Coria y de su gran fortalecimiento defensivo, seguramente en éste se refleja la gran importancia que coge posteriormente. Al-Idrisi la menciona como castillo aunque termina de redactar su obra después de la conquista de Coria ${ }^{62}$.

Junto a Cáceres, Trujillo también tenía una gran importancia defensiva, representando la llave defensiva de la parte oriental de Extremadura. Su dinámica va a ser, sin embargo, en el periodo que estudiamos, muy distinta a la de Cáceres. Salvo Gerardo Sempavor, los cristianos no intentarán la conquista de Trujillo hasta su definitiva carda en 1234 (ya estaban en manos cristianas por entonces Cáceres, Mérida, Badajoz y Montánchez), cuando el nuevo mapa político hacia indefendible la ciudad, pues era posible realizar un asedio continuado sin ningún riesgo. Esto explica que no sea una hueste real sino el obispo de Plasencia ayudado por las ordenes militares los que conquisten Trujillo ${ }^{63}$. Estamos, por tanto, pese a estas circunstancias, ante un lugar con fuertes defensas y de muy dificil conquista en condiciones normales. No podía ser de otro modo: los almohades concedían el mismo valor estratégico a Cáceres y a Trujillo, pues su ubicación revestía las mismas características. Además, en el caso trujillano la solución era más fácil. No se trata, como en Cáceres, de un núcleo poblacional que cobra de momento una gran importancia. Trujillo ya la tenfa. Ya hemos señalado como aparece siempre mencionado como ciudad, y ello no sólo en el siglo XII: en el periodo califal al-Farisi al citarlo entre otros lugares señala que "todas son grandes ciudades"; Ibn Hayyan cita al gobernador de Trujillo entre los de las tahas más importantes de la España musulmana ${ }^{\text {os }}$. Por todo ello, aparecía dotado de notables defensas. Esto explica que el

\footnotetext{
${ }^{62}$ FuENTES, I, 402; AL-IDRISI, Bbid., p. 84.

${ }^{63}$ Anales Toledanos, II, 408.

64 Fuentes, I, 70; IBN HAYYAN, Crónica del califa Abderramán III an-Nasir, p. 193.
} 
cumplimiento por Trujillo de su nuevo papel no necesitará de especiales obras defensivas. Ya a finales del siglo IX o principios del X contaba con una magnifica alcazaba de grandes muros y extension, que unia al propio castillo (un cuadrado de mas de 50 metros de lado) un albacar de superficie no muy inferior a una hectárea ${ }^{65}$. A la solidez de la alcazaba se unía la de los muros de la ciudad, realizados con mamposterfa y sillerfa, aún hoy en gran estado de conservación. Trujillo, por tanto, estaba preparado para jugar un papel similar al de Cáceres, pero las prioridades castellanas permitieron que desde su conquista en 1196 por los almohades hasta su carda definitiva en manos cristianas gozará esta plaza preparada para la guerra de una relativa tranquilidad.

Un tercer nivel defensivo en esta primera zona está constituido por las fortalezas que se extienden de este a oeste a la largo de la divisoria de aguas entre el Tajo y el Guadiana. Estamos ante los típicos hisn musulmanes o castillos cristianos, es decir, construcciones defensivas con o sin población adicional pero en todo caso de poca entidad. Esto supone que para su ubicación eligen puntos de dif́́cil acceso. Se constituyen como una barrera de seguridad adicional, aunque su importancia defensiva es considerablemente inferior a la de las dos ciudades extremeñas que hemos visto. Ya hemos señalado las características de la ubicación de castillos como Alburquerque, enclavado en una preeminencia rocosa, Montánchez o Santa Cruz. Estos castillos jalonan las sierras de San Pedro, Montánchez, Guadalupe y las Villuercas. En tierras portuguesas, pero lindando con la Extremadura actual, estaria Marvao; luego vendrían Alburquerque, Montánchez, Santa Cruz, Cabañas y, quizás, Zuferola ${ }^{66}$. Junto a estos castillos es posible que en época musulmana existieran los de Piedrabuena, Mayorga, Azagalla y

${ }^{65}$ Cf. J. LAFUENTE y J. ZOZAYA, Algunas obsenvaciones sobre el castillo de Trujillo, "Actas del XXIII Congreso Intemacional de Historia del Arte", II, Granada, 1973, pp. 119 y 126; también puede verse, G. VELO NIETO, Castillos de la Alta Extremadura, Madrid, 1968, pp: $591-592$.

${ }^{66}$ Este último castillo no ha sido localizado satisfactoriamente. C. NARANJo, Trujillo. Sus hijos y monumentos, Madrid, 1983, pp. 57 y 63, y P. HURTADO, Castillos, torres y casas fuertes de la provincia de Cáceres, Cáceres, 1927, pp. 325-326, creen en su posible ubicación en la confluencia de los ríos Tozo y Almonte, en Villavieja, donde está la villa murada de Los Azuquepes, aunque no lo afirman con rotundidad; G. VELO Y NIETO, Bid., p. 674, aunque anota estas opiniones no se inclina por aceptarlas totalmente y no sugiere ningún emplezamiento concreto. Está claro que debería estar cerca de Trujillo y Cabañas del Castillo, por lo que no es imposible que se situase en la sierra de las Villuercas. De estar en el lugar propuesto, se ubicaría muy cerca de la frontera pactada entre Castilla y León. 
Esparragal ${ }^{67}$, situados todos próximos al de Alburquerque. Salvo el de Piedrabuena, que está enclavado en una llano, todos los demás están ubicados en magnificos emplazamientos naturales de muy fácil defensa ${ }^{68}$. No es segura en esta época la existencia del hisn de Logrosán; en cuanto al de Cañamero, sólo es utilizado transitoriamente por Sancho Fernández, hijo de Fernando II y hermano de Alfonso IX ${ }^{69}$.

El emplazamiento de los castillos de este tercer nivel defensivo parece estar muy vinculado a la protección de las vías de comunicación. Asf, el de Alburquerque se sitúa entre Alcántara y Badajoz; el de Montánchez; entre Cáceres y Miknasa (si aceptamos la proximidad entre esta ciudad y la actual Villanueva de la Serena); y el de Santa Cruz, entre Medellín y Trujillo. Los tres trayectos están recogidos por al-Idrisi (el segundo ya no existiría por la desaparición de Miknasa), pero ya aparecian en Ibn Hawqal (siglo X). Los castillos de Santa Cruz y Alburquerque (si aceptamos la denominación árabe de Karkar o Karkay) ya existían en la época califal; la primera mención de Montánchez se remonta a $1095^{70}$. Son, por tanto, fortalezas de larga existencia que simplemente cambian su funcionalidad cuando la defensa extremeña, tras la pérdida de Coria, tenga que reestructurar-

${ }^{67}$ Los tres primeros aparecen mencionados en 1264 , en relación con un problema de términos entre la Orden de Alcántara y Badajoz; se habla con claridad del término de Azagala, lo que parece dar por sentado que no se tratan de realidades recientes. (I. J. ORTEGA Y COTES, Ibid., doc. 35); el castillo de Esparragal aparece mencionado en una bula de Gregorio de 1235 en unión con sus villas, lo que parece denotar igualmente una existencia de cierto tiempo (Ibíd., doc. 18, p. 43).

${ }^{68}$ Cf. A. Navareño Mateos, lbid., pp. 121, 150, 174 y 209.

${ }^{69}$ El castillo de Logrosán es citado por Yaqut (G. 'ABD AL-KARIM, La España musulmana en la obra de Yaqut (s. XII-XIII). Repertorio enciclopédico de ciudades, castillos y lugares de al-Andalus, extraido del Mucyain al-buldan Diccionario de paises), Granada, 1974, $n^{\circ}$ 325) pero no hay garantía alguna de que este geógrafo musulmán no aludiera a realidades cronológicamente anteriores a su diccionario. Por otro lado, la documentación cristiana del concejo de Trujillo es prácticamente nula hasta mediados del siglo XIV, por lo que la ausencia de menciones a este lugar. tampoco significa taxativamente su inexistencia en este periodo. Es más significativo, sin embargo, y apunta en este sentido, que las fuentes cristianas de la época de la conquista no aludan a él. Conviene tener en cuenta, pese a todo, que no es algo absolutanente excepcional: sucede lo mismo por ejemplo con el de Lobón que sólo aparece más tarde en las fuentes cristianas y de modo indirecto y casual; tampoco aparecen datos sobre la conquista de otros castillos situados en la Siberia extremeña o en el sur de Badajoz. En relación con el segundo castillo citado, sabemos que Sancho Fernández con un grupo de personas que había reclutado supuestamente para servir al califa almohade "fue a Cañamero, un castillo ermo, e poblolo, c fizo mucho mal ende a inoros, e a christianos", ocupación efímera porque fue matado por un oso poco después y los inusulmanes acabaron pronto con este nido de handidismo (Anales Toledanos, II, p. 405).

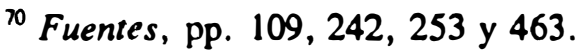


se. De todos estos castillos, sólo Montánchez aparece dotado con seguridad de una población no ligada de modo exclusivo a la defensa de la fortaleza; los demás parecen tener una finalidad exclusivamente defensiva lo que nos muestra una zona de escasa ocupación humana.

Estos castillos están dotados de cierta solidez defensiva. Ibn Idari dice de Montánchez que era "una de las fortalezas de mayor elevación, renombrada por lo abrupto y fortificado"; el hijo del rey de Badajoz Mutawakkil, alMansur, se puso a salvo precisamente en Montánchez. En Alburquerque fue capaz de resistir en condiciones difíciles Alfonso Téllez, años antes de la conquista de Cáceres ${ }^{71}$. En cualquier caso, su importancia no trasciende la de simples castillos con efectivos limitados, en función de su papel en gran medida estrictamente defensivo. Las condiciones de su conquista son aclaratorias: Montánchez es conquistado por la orden de Santiago "cum paucis" y Santa Cruz, por las ordenes militares ${ }^{2}$. Son, por tanto, puntos defensivos que aisladamente ofrecen una resistencia limitada y que no inquietan a los cristianos: tras la conquista de Cáceres, Alfonso IX se encamina a Mérida y Badajoz sin que le preocupen estos castillos, con capacidad simplemente defensiva, que deja como labor de las órdenes militares.

La zona puramente fronteriza de la Extremadura musulmana con sus dos centros estratégicos de Cáceres y Trujillo y con otros centros defensivos que se almoldan al típico hisn musulmán o castillo cristiano y que protegen pasos del Tajo y vías comunicación a través de estribaciones montañosas se configura como un sistema defensivo sólido que resultó de conquista nada fácil.

En la zona oriental de la actual provincia de Badajoz (la Siberia extremeña y la parte más oriental de la Serena) se configura, al igual que entre el Tajo y las estribaciones montañosas situadas más al sur, una zona ampliamente fortificada. En realidad, el papel de los centros de hábitat establecidos en la misma no trascienden un papel casi exclusivamente defensivo. Choca la proliferación de las defensas con el nulo papel de estos centros fortificados en las vías de comunicación (ninguno aparece citado en las vias de al-Idrisi). Sólo los caminos, secundarios, de Mérida a Caracuel

${ }^{7}$ Fuentes, I, p. 463; A. HUICI MIRANIDA, Crónicas árabes de la Reconquista, II, p. 193; R. MAR'INEZZ Y MARTINEZ, lbid., pp. 375-376.

${ }^{72}$ Crónica latina de los reyes de Castilla, p. 79; Anales Toledanos, II, p. 408. 
o de Albalat a Calatrava podían aproximarse a esta zona. Tanto en las vías Toledo-Córdoba como Badajoz-Córdoba quedaba situada marginalmente. A esto se une que las fortificaciones que la pueblan no aparecen en las fuentes árabes: es la documentación cristiana de la época de la conquista la que alude a estos castillos. Todo nos hace pensar que su desarrollo es reciente y que no podía ser muy anterior al papel estratégico que desempeña esta zona en la segunda mitad del siglo XII. La carda de los almorávides y el control por Castilla de puntos como Calatrava, Salvatierra, Piedrabuena o Calatrava la Nueva, hacía posible la penetración en el bajo valle del Guadiana bien siguiendo el curso del róo o por la vía que ofrecían el Zújar y el Guadamez. De este modo, y de pronto, una espacio marginal aparece dotada de una gran importancia estratégica.

Los restos actuales de los castillos de esta zona no permiten grandes precisiones sobre su época de construccion, pues han sufrido grandes transformaciones cuando no han sido reconstruidos ex novo. Sin embargo, Benquerencia, que conserva mucho de su construcción original, parece tener una gran huella almohade ${ }^{73}$.

En cualquier caso, el desarrollo de fortificaciones en la zona, creemos que por los almohades, tuvo sobre todo un carácter preventivo. Castilla tiene otras prioridades y sólo, con la brevedad que caracteriza a los Anales Toledanos, tenemos noticia de que en 1187 Alfonso VIII tomo Reina, Magacela y Baños ${ }^{74}$. Al menos para Magacela, Alfonso VIII debió atravesar la zona oriental de Badajoz, pero ante la ausencia de información sólo podemos suponerlo. Es llamativo que elija Magacela y no alguna fortificación situada más al este, más próxima a los puntos controlados por los castellanos. Muy distinta es la actuación de su nieto, Fernando III ante Capilla. Estamos ante una muy importante fortificación: su conquista aparece en diversas crónicas y es señalada al lado de las de Ubeda, Martos, Iznatoraf y Quesada entre otras ${ }^{75}$. El castillo de Capilla es presentado como "castrum nobile, fortissimum et famosum", "inexpugnabile" y "munitissi-

${ }^{73}$ A. NAVAREÑo, lbid., pp. 305-306.

${ }^{74}$ Anales Toledanos, I, pag. 393.

75 "Era MCCLXXI. Capta fuit Ubeda, et Martos cum allis circunstantibus Castris et villis, Baeza, et Capiella, et San Estevan. Andujar, et Aznatoraf, et Quesada, Xodar et allis" (Anales Compostelanos, p. 324). 
mum"76. Sólo pudo ser controlado por los cristianos tras catorce semanas de asedio y por la capitulación de los sitiados, tras tener la certeza de que no podran recibir ayuda del exterior, todo ello pese a utilizarse "machinis mirificis"; pero la realmente llamativo es que tras la muerte del rey de Baeza y cuando algunos aconsejan al rey castellano que vaya a Andalucía, éste, aconsejado por su madre Berenguela, decide continuar ${ }^{77}$. Capilla aparece como una castillo de elevado valor estratégico que suponía al menos una retaguardia poco recomendable, no de otro modo se explica el prudente consejo de la reina madre.

Capilla debra ser con toda seguridad el castillo más importante y consistente defensivamente de la zona. Contrasta la importante información que tenemos sobre él con la parquedad de la que versa sobre las demás fortalezas, de las que desconocemos prácticamente las condiciones de su conquista $^{78}$. Quizás su ubicación contribuya a explicar esto: estaba situado en una de las entradas más cómodas al valle del Guadiana siguiendo el valle del Guadamez y, luego, el del Zujar y más al este que las demás fortificaciones de la zona salvo las situadas próximas al Guadiana.

Las restantes fortificaciones aparecen en el momento de la donación: Almorchón en 1236, Alcócer en 1245 y Benquerencia en $1241^{79}$. Desconocemos la fecha exacta de su conquista. Tras la calda de Capilla, estas fortificaciones parecen perder interés y no representar ningún peligro para la retaguardía castellana.

Rodeado en Extremadura al norte y al este por dos barreras defensivas, el valle del Guadiana aparece también dotado de unas sólidas fortificaciones. Las barreras señaladas permiten a esta zona constituirse como una relativa retaguardia, aspecto que tendrá una gran importancia en cuestiones relacionadas con la producción y la ocupación del espacio. La proliferación de las estructuras defensivas es prácticamente inherente a cualquier socie-

\footnotetext{
${ }^{76}$ Crónica latina de los reyes de Castilla, p. 71; R. JIMÉNEZ DE RADA, Historia de Rebus Hispaniae sive Historia Gothica, (edic. de J. FERNANDEZ VALVERDE), Tumholt, 1987, p. 294.

"Crónica latina de los reyes de Castilla, p. 71; R. JIMÉNEZ DE RADA, Ibld.

7 Hay una excepción: Zalamca fue conquistada por la orden de Alcántara tras muchos días de asedio dado que el castillo tenía solidas defensas y los habitantes de la villa se refugiaron en él (M. R. MARTINEZ Y MARTINEZ, lbid., pp. 425-426; el documento está recogido de Antonio de SAN FELPE, Milagros del santisimo Cristo de Zalamea, Madrid, 1745, p. 71, que lo tomó del archivo municipal).
}

${ }^{79}$ J. GonZ.ÁleZ, Fernando III, III, docs. 579, 680 y 726. 
dad medieval y, por supuesto, a la hispanomusulmana. Por tanto, la zona contaba con numerosas fortificaciones desde los primeros momentos de la ocupación árabe. Pero los almohades desarrollarán además una labor constructiva tendente a dar mayor solidez a una zona que abría las puertas del valle del Guadalquivir y especificamente a Sevilla, la más importante ciudad musulmana del momento. Es por ello por lo que construyen prácticamente de nuevo las fortalezas de Reina y Montemolín ${ }^{80}$. En Badajoz, como veremos y ya hemos mencionado, su contribucion es considerable. Pero, posiblemente, la labor constructiva almohade en esta zona extremeña trasciende los tres centros señalados. Aunque no puede afirmarse tajantemente, el uso del tapial o la existencia de torres albarranas hace posible la existencia de trabajos almohades de mejoramiento de las defensas en otras fortalezas ${ }^{81}$. No es aventurado pensar que, tal y como las encontraron los cristianos, las fortificaciones de esta zona debran mucho a los almohades.

El valle del Guadiana se estructura en dos líneas defensivas fundamentales. La primera se extiende a lo largo del Guadiana, o muy proximo a él, y cuenta con lugares como Badajoz, Mérida o Medellín, estos dos últimos con más pasado que presente en el momento de la conquista. Una segunda línea se desarrolla en las estribaciones montañosas del sur de la provincia de Badajoz con centros como Jérez, Montemolín, Reina o Azuaga, que en general están situados en importantes vías de comunicación. Las fortalezas situadas entre el Guadiana y sierra Morena son escasas: en los trayectos señalados por al-Idrisi se pasa de Azuaga a Alange y de Jérez a Badajoz, con distancias superiores a las habituales; sólo una segunda ruta a Cordoba, seguramente secundaria, hace una escala intermedia entre Merida y al-K.R., en Hornachos ${ }^{82}$. El centro de la provincia de Badajoz tiene asi

\footnotetext{
${ }^{80}$ Reina aparece citada por al-Idrisi como simple centro del paso entre Córdoba y Jérez, sin que se especifique nada sobre su carácter fortificado (Los caininos de al-Andalus, p. 82). Montemolín, al contrario es presentado como fortaleza por Ibn Jaldun (siglo XIV) en el año 271 de la héjira (O. MACHADO, Historia de los árabes en España, por Ibn Jaldun, "Cuadernos de Historia de España", VII (1947), p. 156).

${ }^{81}$ Sin ánimo de ser exhaustivos podemos citar el caso de Homachos, donde predomina el típico tapial musulman y hay una torre albarrana, cuyos restos árabes considera M. GARRIDO SANTIAGO que son de los siglos XI y XII (Arquitectura militar de la orden de Santiago en Extremadura, Cáceres, 1989, p. 151), Magacela o Azuaga (la actual fortaleza es más tardía pero la anterior árabe tenía una técnica constructiva muy próxima a los almohades: las fuentes cristianas dirán refiriéndose a sus restos que tenía "las paredes bien anchas, todo bien sano, fecho de tapias e algo de ello de cal y canto"). En cualquier caso, una cronología precisa de las fortificaciones árabes extremeñas está por hacer.
}

82 AL-IDRISI, Los caininos, pp. 80, 82 y 86. 
un vacío defensivo relativo debido a su menor valor estratégico, pues los centros de población más importantes se sitúan en el Guadiana.

El centro defensivo de la zona, y de toda Extremadura (y consiguientemente de la zona hoy portuguesa y entonces bajo dominio musulmán situada al oeste) es Badajoz. Ya desde la primera mitad del siglo X, supera en importancia Mérida, que durante el periodo visigodo y comienzos del dominio musulmán era el centro de Extremadura y de importantes zonas portuguesas, y se dota de importantes murallas ante el terror que produce ia expedición de Ordoño II en el $913^{83}$. A Mediados del siglo XII, las murallas de Badajoz (de las que no volvemos a tener noticias de mejora alguna) debian estar bastante deterioradas o resultar insuficientes. A Geraldo Sempavor, el control de la ciudad propiamente dicha no le resulto demasiado difícil, sobre todo, teniendo en cuenta su entidad demográfica. Sólo la alcazaba parece resistir mejor. Es razonable pensar que durante el periodo de los reinos taifas, se realizase alguna mejora defensiva no sólo en Badajoz sino en otros centros. En cualquier caso, tras la etapa de predominio almorávide, las defensas de Badajoz no parecen estar en buen estado, o al menos en el requerido para lo que los almohades pensaban que se avecinaba. Estos, tras la derrota de Geraldo Sempavor, se dedicaron a reforzarlas. La alcazaba es prácticamente en su totalidad almohade ${ }^{84}$. Posiblemente, las murallas de Badajoz también se mejoraron, aunque su destrucción para hacer otra nueva abaluartada en el siglo XVII impide ninguna opinión taxativa sobre el particular.

Las labores defensivas almohades debieron hacer de Badajoz una ciudad magnificamente defendida. Era vital, pues quien dominará Badajoz dominaría Extremadura. A la fortaleza de sus defensas unía esta ciudad condiciones adicionales derivadas de su ubicación. Por el lado norte, debido al Guadiana era inatacable. Al río se unía una pendiente que utilizaba el

3 Ibn Hayyan cuando narra el considerable mejoramiento de las defensas de Badajoz este año señala como era "la mayor de sus ciudades [de la zona]" (IBN HAYYAN, Crónica del califa 'Abderrahman III an-Nasir, p. 83).

*4 L. TORRES BALBÁs, Ciudades hispanomusulmanas, p. 179, considera que "casi todos los muros y torres que rodean a la alcazaba de Badajoz pertenecen a la construcción almohade de Abu Ya'qub Yasuf"; para sus características tipológicas, cf. pags. 198-202. Ibn Said elogia a Este por la construcción de la alcazaba, dando a entender que prácticamente era de hechura nueva (IBN SAHIB AL-SALA, lbid., p. 66). 
muro exterior de la alcazaba. Por el este, corría el arroyo Rivillas ${ }^{85}$. El ataque de la plaza debra realizarse por los lados sur y oeste, en los que el terreno era llano. De todos modos, la mayor fortaleza de Badajoz era su importante peso demográfico del que ya hemos hablado, pues todos estos detalles a los que hemos aludido no servirían de nada en una fortificación pequeña.

¿Estas condiciones hicieron a Badajoz una ciudad inexpugnable? Su fortaleza defensiva no era inferior a Cáceres. Sin embargo, la fortificación de Badajoz tenía un carácter más preventivo que el de las de Cáceres, ciudad situada en una auténtica marca fronteriza. El sistema defensivo almohade hacía diff́cil la conquista directa de Badajoz. Por ello, la ciudad resiste desde Geraldo Sempavor hasta su definitiva conquista por los cristianos solamente un asedio, en 1226, realizado por Alfonso IX. Este se realiza en toda regla: tras la tenaz resistencia de Cáceres, el rey leonés debió pensar que quizás fuese más fácil descabezar Extremadura conquistando su ciudad central. No sabemos el tiempo que emplea en la labor pero las fuentes hablan de una "longam obsidionem" y sólo se abandono con "spe frustrati" y tras una tenaz resistencia de los pacenses("post innumeras expensas et mortes hominum Sarraceni"). Coincide el asedio de Badajoz con el de Elvas por el rey de Portugal, lo que debilitaba la situación de las dos ciudades. Tampoco Elvas cae en manos portuguesas y por unos años ambas ciudades seguirán bajo el dominio musulmán.

Al margen de este asedio, Badajoz sufrirá pocas expediciones cristianas. Sólo estamos informados de la razzia que realiza Alfonso IX en 1218 en la que "destruyo todas las cosas que eran enderredor de Badajoz"86.

Badajoz no protagonizó aguerridas defensas como Cáceres. Sólo en una ocasion se pusieron a prueba en toda regla sus muros. En 1230, cae en manos cristianos "después de pocos días [de ásedio]" ${ }^{87}$. En este momento, Cáceres es ya una ciudad cristiana y los leoneses no tienen ningún obstáculo serio para llegar al valle del Guadiana. Además, en plena descomposición del poder almohade en la península, las posibilidades de socorro son

\footnotetext{
${ }^{85}$ Esto permitía que se rodease a Badajoz de un foso, pero esto no se hizo en el periodo almohade y sólo consta en el siglo XVII: cf. F. VALDÉs, Ciudadela y fortificación urbana: el caso de Badajoz, "Castrum", p. 147, nota 26.

${ }^{86}$ LUCAS DE TUY, Ibid., p. 422.

${ }^{87}$ lbid., p. 424.
} 
nulas tras la derrota de Aben Hut a manos de Alfonso IX entre Mérida y Alange: Badajoz queda a merced de sus propias fuerzas. Ante la alternativa de un largo asedio sin ningún peligro para el atacante y con durísimas consecuencias para los habitantes de la ciudad, Badajoz opta por una capitulación que pondría personas y enseres a salvo. De este modo, una inexpugnable ciudad cae con enorme facilidad.

La importancia defensiva de Badajoz condiciona fuertemente la táctica conquistadora que castellanos y leoneses llevarán en adelante en Extremadura. Descabezada la defensa, sin posibilidad inmediata de refuerzos de Andalucía, ninguna hueste real recorrerá en las siguientes años las tierras extremeñas. Mientras Fernando III realiza conquistas en Andalucía, Extremadura, que no ofrece como vanguardia ningún problema militar para el reino castellano-leonés, queda como una zona en la que las órdenes militares (que no dejarán de colaborar en la conquista andaluza) realizán la conquista de los puntos fortificados. De este modo, incluso Trujillo cae ante una hueste forzosamente reducida. Sin Badajoz, los diversos castillos y ciudades en las condiciones políticas de 1230-1240 sólo aspiran a resistir. El sistema defensivo queda desestructurado. La ubicación de los puntos aún en manos musulmanas ya no preocupan a los cristianos que no temen posibles ataques de los musulmanes extremeños.

Además de la fortaleza intrínseca de Badajoz, la proximidad de puntos defensivos aumentaba su seguridad. Muy próximo estaba Elvas, que en algún caso es denominada madina; a ésta debemos unir Jurumenha; además el camino de Alcántara a Badajoz parece estar plagado de castillos. Todo ello incidiría en la fortaleza de esta ciudad extremeña.

La línea del Guadiana es una de las más fortificadas de la Extremadura musulmana. Al margen de Badajoz, que tiene una importancia que trasciende la de un punto concreto, sobre este rio está Jurumenha y Elvas, en el actual Portugal y muy próximos a Badajoz, Lobón, Mérida y Medellín. Muy próximos a este lugar se sitúan Magacela y Alange. Estas fortificaciones oscilan entre el típico hisn, como es el caso de Lobón, Alange, Magacela o Jurumenha, y la madina, como Elvas. Mérida, de brillante pasado, y Medellín no parece que llegaran a poder ser denominadas con esta última palabra, pero superarian demográficamente al primer grupo.

Respecto a éste, nuestra información es escasa. Las fuentes aluden casi exclusivamente al tipo de fortificación. Jurumenha es presentada por Ibn Said e Ibn Idari como un castillo; del mismo modo aparece Lobon en la obra del primero y en la documentación de Fernando III, y Alange en los 
Caminos de al-Idrisi; en cuanto a Magacela, que aparece en Yaqût como hisn, las fuentes cristianas nos informan que era un castillo con su villa ${ }^{88}$. Alguna de estas fortificaciones tendrían una escasa entidad. Por ejemplo, Lobón prácticamente no aparece en la documentación cristiana del siglo XIII (su aparición en la árabe es también marginal): no se menciona en absoluto su conquista, lo que si sucede con las restante fortalezas, y cuando es mencionado en 1269 es por una donación de heredades en Guadajira, en la que aparece entre los limites ${ }^{89}$. Tanto Magacela como Alange responden por su ubicación al típico castillo o hisn, al estar enclavados en puntos elevados que diticultan el acceso y la conquista de los mismos. La situación es distinta para Lobón, que esta junto al Guadiana: la pendiente del lado del río es muy elevada, pero por el sur no hay ninguna pendiente y el castillo de este modo ofrece un flanco débil. En realidad, serfa indefendible en una primera línea fronteriza, pues el Guadiana no supone tampoco una defensa considerable.

Un perfil distinto ofrecen Elvas, Mérida y Medellín. Su importancia es considerablemente mayor, como muestra su integración en las vías de comunicación de la España musulmán (De los puntos anteriores, sólo Alange aparece en el trayecto Córdoba-Badajoz por la gran calzada de Ibn Hawqal y su importancia, dada su proximidad a Mérida debra ser limitada). Elvas aparece en la vía Badajoz-Lisboa; Mérida se cita en los trayectos a Córdoba, salvo en el más reciente que busca un camino más directo a Badajoz por Jerez de los Caballeros, y está comunicada con Caracuel, Alcántara y Medellín; esta última población lo está además de con Mérida con Trujillo. Son, por tanto, poblaciones que tienen un protagonismo importante en las vías de comunicación y que junto con Jerez de los Caballeros, Miknasa antes de su desaparición, Alcántara o Albalat formarían el grupo que sigue jerárquicamente en este campo a Badajoz. En estas circunstancias, es de esperar que estemos antes poblaciones que no sean simples puntos fortificados, con las implicaciones económicas y demográficas que ello

Jurumenha: IBN SAHIB AL-SALA, Ibid., p. 138, y Fuentes, I, 402 y 405; Lobón: IBN SAHIB AL-SALA, Ibid., p. 233; Alange: AL-IDRISI, Los caininos, p. 82 (Fuentes, I, pag. 129), y J. GONZALEZ, Femando III, III, doc. 715; Magacela: G. ABD AL-KARIM, Ibid, p. 89, no 45, y J. GONZALEZ, Femando III, III, doc. 521.

${ }^{89}$ F. SANtos Coco, Documentos del Archivo-Catedral de Badajoz, "Revista del Centro de Estudios Extremeños", IX (1935), doc. 17. 
conlleva. Elvas aparece en al-Idrisi como madina ${ }^{90}$ y tendría un peso demográfico posiblemente no muy diferente del de Trujillo o Cáceres. Medellin es presentado siempre como hisn pero el mismo al-Idrisi nos dice que está muy poblado y al citar la provincia de al-Balat (la única mención existente) lo presenta como la población más importantes junto a Albalat (que se despuebla inmediatamente después de la conquista de Coria) ${ }^{91}$. En cualquier caso, no podemos calcular ni por aproximación la probable población de esta localidad extremeña.

Mérida ofrece unas circunstancias especiales. Antes del desarrollo de Badajoz era una de las más importantes ciudades de la España musulmana, al igual que antes lo fue de la visigoda. Sin embargo, paulatinamente ira perdiendo importancia hasta no ser sino un elemento más dentro de la estructura defensiva de la Extremadura musulmana. En las fuentes cristianas aparece como "oppidi parvi" 2 . De todos modos, dotada de su alcazaba y de sus murallas y enclavada en una zona fertil, aún cuando hubieran disminuido mucho sus efectivos demográficos, segura siendo una de los puntos defensivos importantes y con una entidad muy superior a la de los simples castillos.

¿Era sólida la línea defensiva del Guadiana? ¿Tenía la fortaleza que creemos haber demostrado para la formada fundamentalmente por Cáceres y Trujillo? En este caso nos situamos en condiciones muy especificas. Ya hemos visto como Badajoz, la mayor fortaleza y con efectivos demográficos que multiplicaban el de cualquier otra población extremeña, cae con cierta facilidad. A todas las fortificaciones de la línea del Guadiana les sucede lo mismo después de la derrota de Aben Hut, que las deja en una absoluta soledad. En estas condiciones no se podía esperar ninguna defensa aguerrida. Por otro lado, como hemos señalado, tras la calda de Badajoz la conquista extremeña queda a cargo de las huestes de las órdenes militares, que serán las que tomen Medellín, Magacela y Alange ${ }^{93}$. Hay dos detalles llamativos que parecen abogar por una mayor endeblez defensiva de esta línea (lo cual no deja de ser normal, si tenemos en cuenta que su función es

\footnotetext{
${ }^{90}$ AL-IDRISI, Los caminos, p. 82.

91 AL-IDRISI, Geografia, pp. 163 y 177.

22 "civitatem antiguam fuınosam, que tune redacta est ad instar oppidi parvi" (Crónica latina de los reyes de Castilla, p. 79).

${ }^{93}$ Anales Toledanos, II, p. 408.
} 
distinta, pues su conquista y defensa es imposible sin romper las líneas defensivas más septentrionales) y por una psicología menos combativa. Alfonso IX, antes de la derrota de Aben Hut, asedia Mérida, en una campaña con objetivos más amplias, "cum parte milicie sue non multa, cum quibusdam et conciliis", lo que contrasta claramente con las campañas de Cáceres (conquistada sólo el año anterior, con similares condiciones políticas en la España musulmana). Hay otro detalle muy significativo: tras la derrota de Aben Hut, los de Elvas, presos del miedo y antes de la calda de Badajoz, abandonan precipitadamente la ciudad ${ }^{94}$. Alfonso IX considera, por las características de su hueste, que las campañas del Guadiana, quizás con la excepción de Badajoz, debran ser menos difíciles que las de Cáceres, donde a la fortaleza de la ciudad se había unido una gran decisión de los defensores. Su hueste es una hueste limitada, pese a estar en un terreno plagado de defensas musulmanas. La precipitada huida de los habitantes de Elvas (algo que no es excepcional, tenemos el caso de Albalat, pero en primera línea de frontera y con efectivos muy inferiores) muestra un carácter menos decidido. Estas condiciones hacen del último año de reinado del último rey privativo de León el más fructifero en conquistas.

Se aprecia claramente una línea defensiva a la largo de las estribaciones montañosas, muy suaves, del sur de Badajoz. Se extiende, especialmente, a lo largo de Sierra Morena, aunque en esta línea habría que incluir a Jerez de los Caballeros, pese a situarse al norte del río Ardila. En esta línea se realizan importantes obras por parte de los almohades: ya hemos indicado los casos de Reina y Montemolín. La práctica desaparición de los restos árabes en las fortalezas que formaban esta línea nos impide saber si las obras almohades fueron más numerosas. La finalidad de esta línea defensiva es clara: protege los pasos hacia el valle medio y bajo del Guadalquivir. Jerez (en las dos vías Sevilla-Badajoz y en la de Córdoba-Badajoz), Azuaga (Cordoba-Badajoz; Cordoba-Miknasa; aparece comunicada también

\footnotetext{
14 "Habitatores Iclves, audito quod Avehut et qui cum eo erant sucubuerant in prelio, relicto predicto castro, noctu fugerunt. Revertentes autem fratres quidam Portugalenses de bello, in quo fuerant cum rege Legionis, portas predicte ville invenenunt apertas et intrantes et neminem invenientes retinuerunt ipsum castrum, id ipsum regi Portugalie significantes" (Crónica latina de los reyes de Castilla, p. 80).
} 
con al-Gilal y Viandar), Reina (Cordoba-Badajoz) y Sigunsa ${ }^{95}$ (Sevilla-Badajoz) se sitúan dentro de las vfas de al-Idrisi ${ }^{96}$.

El centro fortificado de mayor entidad es Jerez de los Caballeros, con un recinto amurallado de 14,4 hectáreas (casi el doble que Cáceres) y con su correspondiente alcázar. Este recinto, sin embargo, se remonta a los siglos XIII y XIV y, por tanto, es cristiano. No es imposible que se aprovechara el trazado árabe, pero sobre el particular no se puede llegar a ninguna opinión concluyente ${ }^{97}$. Todo parece indicar que Jerez estarfa dentro de ese grupo de fortificaciones que aún apareciendo siempre o normalmente como hisn o castillos en las fuentes estarian en el grupo de las que se aproximarían a la categoría de ciudades y que se sitúan en Extremadura inmediatamente, aunque a mucha distancia, de Badajoz.

Los demás lugares que forman esta línea fortificada son típicos castillos que cuentan en su caso con una villa. Asi sucede con Reina ${ }^{2}$. No es seguro que tuviera esta misma estructura Montemolín (en el documento de donacion, en contra de lo que es habitual, no se especifica nada sobre el particular); sin embargo, todo parece suponer que ası era: su amplio término parece chocar con el hecho de que solo fuera un simple castillo y muy pronto se constituye como un importante centro del señorfo santiaguista9.

Los demás centros fortificados aparecen o bien en las fuentes árabes, poco precisas, o bien de modo marginal en las fuentes cristianas más tempranas tras la conquista. Sólo se especifica su categoría de castillos. Asf sucede con Azuaga, Fregenal, Valera o Sigunsa ${ }^{100}$.

Todo parece indicar que no son lugares de intensa población, salvo . Jerez, debido a su importancia en las vías de comunicación musulmanas. Predominan los castillos con o sin sus correspondientes villas, que no pare-

9s Aceptamos la ubicación hipotética de M. TERRÓn ALBARRÁn, Extremadura musulmana, p. 317, que sitúa este castillo en la actual sierra de la Gigonza, cerca de Segura de Lón, ubicación que parceen ratificar dos demarcaciones de 1253 (límites entre los concejos de Sevilla y Badajoz) y 1258 (confirmación por Alfonso $X$ de los términos concedidos por Alfonso IX a este último).

9 AL-IDRISI, Los caminos, pp. 80, 82, 83, 86 y 87.

${ }^{7}$ M. GaRrido Santlago, Ibld., pp. 170-171.

92 J. GonzAlez, Fernando III, III, doc. 739.

99 J. Gonzalez, Femando III, III, doc. 763; ef. H. MOTA ARŕvalo, El castillo de Montemolin, "Revista de Estudios Extremeños", XV (1959), pp. 367-374.

100 AL-IDRISI, Los caminos, pp. 82 y 87; E. RODRIGUEZ AMAYA, Ibid., pp. 12-13; J. GONZALEZ, Femando III, I, p. 195, nota 434. 
ce que estuvieran fortificadas. Es llamativo que la mayor parte de estos lugares aparecen en las fuentes árabes en relación con los caminos, pero no con su importancia defensiva. A esto se une que no tenemos información de la fecha exacta ni de las circunstancias de la conquista de estos centros en fuentes de primera mano. Todo hace pensar que esta línea se hundio y no creo excesivos problemas tras el control cristiano de la línea del Guadiana. El retraso en la conquista de algunos de esto puntos hay que atribuirlo al interés en otros de mayor envergadura ${ }^{101}$. El rey castellano consideraba que no amenazaban la retaguardia cristiana en su avance por Andalucia y los cronistas no les daban suficiente categoría como para introducir la fecha de su conquista en sus narraciones. Sin embargo, como parte de un todo, esta línea si debio estar dotada de solidez, de otro modo no se entenderían los afanes almohades. El intento de controlar Jerez ${ }^{102}$ por Fernando II parece mostrar la importancia geopolítica que para este rey tenía esta ciudad tan meridional.

Ya hemos señalado como en el centro de la actual provincia de Badajoz parece tener un cierto vacío defensivo. Al menos no hay una línea defensiva. Sin embargo, el castillo, que no tiene una función exclusivamente defensiva, no está ausente. Hornachos es un ejemplo de ello. Debió influir en esta realidad la escasa importancia geopolítica de la zona y su menor participación en las vías de comunicación. Hornachos aparece en una de las vías que comunicaban con Córdoba; contaba con villa y castillo ${ }^{103}$. Es posible que también se situasen en esta zona algunos castillos o hisn que aparecen aisladamente en las fuentes árabes en el periodo que estudiamos pero que no vuelven a mencionarse y son de ubicación dudosa ${ }^{104}$. Sin embargo, es sintomático de una mucha menor abundancia de fortificaciones en el centro de la provincia pacense el que en los trayectos Badajoz-Córdoba y

\footnotetext{
101 Reina no estaba aún conquistada en 1246 y Femando III la donó sin embargo a la Orden de Santiago, señalando que "si yo tregua fiziere con Sevilla ante que yo gane Reyna o ante que vos la ganedes, que entre en la tregua de Sevilla" (J. GONZÁLEZ, Femando III, III, doc. 739).

${ }^{102}$ Cf. nota 7

${ }^{103}$ AL-IDRISI, Los caminos, p. 86; J. GONZALEZ, Femando III, III, doc. 553 (solo hace referencia a la villa).

${ }^{104}$ Podemos citar los casos de Atranques, Al-Arya y Al-Falal (Fuentes, I, pp. 406 y 407; A. Huici Miranda, Noticias de los reyes del Mogreb e historia de la ciudad de Fez, Valencia, 1918, p. 107).
} 
Badajoz-Sevilla se pase de Jerez a Badajoz sin ningún punto intermedio, pese a que la distancia haría normal que se invirtiese en ello dos etapas.

Además de Hornachos, está fuera de la línea del Guadiana, pese a su proximidad a este rio, al situarse en una zona donde ha tomado una dirección norte/sur en vez de la este/oeste que tiene entre Medellín y Badajoz, y de la que se forma en el sur de la provincia Alconchel ${ }^{105}$.

\section{El ESPACIO}

Hay dos aspectos relacionados con este apartado de gran interés: la estructuración político-institucional del espacio y la desigual ocupación del mismo en lo que parece una dicotomía frontera/retaguardia.

En lo que respecta al primer aspecto, se aprecia una ruptura total entre la división espacial en coras de la época califal y las pautas que rigen este campo en el periodo que estudiamos ${ }^{106}$. Esto aparece con gran claridad dado el gran conservadurismo de la geografía árabe. En muchos casos se citan hisn e incluso madina dependientes de Mérida, la principal ciudad extremeña durante el califato y cabeza de una cora ${ }^{107}$. Sin embargo, no sucede lo mismo con Badajoz, que nunca aparece con castillos dependientes. Se ha pasado, por tanto, de una estructura centralizada que coge amplios espacios a otra en que, aunque sin perder su carácter jerárquico, los diversos puntos gozan de autonomía.

En el periodo que nos ocupa las ciudades y los castillos son los elementos estructurantes de la división espacial. No se documentan en general relaciones de subordinación ${ }^{108}$. Esto origina que en función de su

105 J. GonZALEZ, Femando II, p. 423, año 1171.

106 J. VALL.VE, La división territorial de la España musulınana, Madrid, 1986, pag. 251, considera que con los almorávides este cambio está ya matcrializado.

107 Los ejemplos son numerosos. Por citur un sólo autor, en el diccionario de Yaqut aparecen, como dependientes de Mérida, Al-Sujaira, Al-Yinah, Baytarat-Luss, Laqant, Lanyas, Logrosán, Medellín, Miknasa, Santa Cruz, Trujillo, Umm Gazzala y Umm Yafar: cf. G. ABD AL-KARIM, Yaqut, n' 44, 45, 112, 117, 130, 214, 224, 314, 326, 340 y 356.

108 Es lo normal: por ejemplo, Alange, pese a su proximidad a Mérida, conserva su autonomía; de este modo, el alfoz emeritense, tan extenso en otras direcciones (límita entre otros con el de Cáceres), aparece muy limitado en dirección sureste. Aparecen, sin embargo, pequeños castillos que no parecen ser autónomos o al menos no dieron origen a un alfoz en el periodo cristiano. Pongamos algunos ejemplos: en las delimitaciones de Badajoz y Cáceres aparecen los castillos de Nadit, Valera, Sigunsa y Tamuja (E. RODRIGUEZ AMAYA, Ibíd., pp. 
desigual importancia, haya espacios jurisdiccionales de gran extension junto a otros muy pequeños que contarfan con poco más que el castillo y una pequeña población ${ }^{109}$. Asimismo, hay términos con límites conocidos, según consta en las fuentes cristianas, y otros de extensión imprecisa, debido a la desigual ocupación del espacio. Como consecuencia de todo lo que acabamos de señalar, la mayor parte de las castillos y ciudades que estructuran la defensa se convierten, bajo el dominio cristiano, en concejos con su propio alfoz independientemente de su dependencia jurisdiccional.

Las alquerías también parecen jugar un papel en la estructuracion del espacio. Posiblemente contarían con uno propio dentro del cual la comunidad aldeana tendría ciertas atribuciones. Sin embargo, no es seguro, que, al contrario que los castillos y ciudades, no tuvieran alguna dependencia. Sólo contamos con un caso, la alquería de Besnageth, concedida por Fernando III a la Orden de Santiago "con su torre et con sus terminos et con sus pertenencias, assi como los mejor ovo en tiempo de moros"110. En el documento de donación no se indica ninguna dependencia respecto de ningún otro centro organizador del espacio; pero es un ejemplo solitario en la documentación. Sin embargo, y pese a la limitada información que tenemos sobre todos aquellos centros sin una gran importancia defensiva, hay indicios para pensar que estos núcleos poblaciones y otros inferiores estuvieron bajo la dependencia de importantes centros defensivos. La documentación árabe nos informa de la existencia de diversas zonas agrarias dependientes de Badajoz que contarfan con su correspondiente poblacion; asimismo, nos consta no mucho después de la conquista la existencia de Calamonte, que estaba incluido dentro del término emeritense ${ }^{111}$.

Respecto a la segunda cuestión que enumeramos, el grado de ocupación del territorio de la Extremadura musulmana en su etapa final, los problemas que se plantean no son pequeños. Las fuentes presentan numerosas limitaciones, dado su interés casi exclusivo en los puntos de importan-

12-13, y P. LUMBreras VALENTE, lbid., p. IX ).

100 El témino asignado al castillo de Almonchón se extendía una legua por todos lados menos por Capilla, dirocción en la que alcanzaba unos diez kilómetros; en total, su superficie no suporaba los cien kilómetros cuadrados, cifra ridícula frente a los do Badajoz, Cáceres, Trujillo, Mérida o Montemolín.

110 J. GONZÁlEZ, Femando III, III, doc. 763.

i'I I. J. ORTEGA Y COTES, Ibld., doc. 14 (no se especifica que estó dentro del alfoz pero se siture dentro de aus límites). 
cia defensiva, y dentro de éstos en los más importantes. El poblamiento rural, que a lo sumo cuenta en los alquerfas con una torre, sólo aparece em escasas ocasiones en relación con límites u otra incidencia. Además, la información de las fuentes árabes sobre el particular es poco aprovechable, pues, dado el conservadurismo de la geografía árabe, no hay seguridad de que aludan a aspectos relacionados con nuestro periodo de estudio, aunque si lo sean los informantes. Por otro lado, en Extremadura no contamos con libros de repartimiento que nos proporcionen un inventario del poblamiento musulmán. Como la repoblación extremeña es deficiente, posiblemente muchos lugares de poca importancia desaparecieron sin dejar huella alguna. Por ello, tenemos que acercarnos al tema del poblamiento y de la demografia musulmanes con mucha cautela y mediante hipotesis.

En cualquier caso, es logico pensar que la frontera debio incidir fuertemente en el poblamiento extremeño, o al menos en las zonas más expuestas a las expediciones y razzias cristianas. Ciertas referencias, no muy concretas nos hacen pensar que la Extremadura del valle del Tajo y, sobre todo, del Guadiana debla estar más poblada en la época califal o en la aftasi que en la etapa final del dominio musulmán. Los laudes a Badajoz (con todo lo formal que puedan ser) nos presentan una zona de abundante riqueza agraria y pecuaria. Esto se ve reflejado en la obra de Yaqub, que nos muestra una realidad anterior a la de la época de la conquista cristiana, en la que Badajoz, como cualquier otra ciudad musulmana enclavada en una tierra fertil, aparece con un término en donde hay un numeroso poblamiento rural ${ }^{112}$. Quizás dentro de esta tendencia deba entenderse la información de al-Idrisi de que esta ciudad "tenfa un barrio más grande que la

112 Al-Razi (siglo X) nos dice que Badajoz "tiene bajo su dependencia un vasto territorio de los más favorables de España en el cultivo de cereales, posee también muchas viñas. Es igualmente la mejor región para la cría de animales, la caza y la pesca. Se encuentra sobre el ró Guadiana, que es abundante en excelente pescado" (Fuenses, I, 96). El Dibr Bilad al-Ardalus (siglo XIV) se refiere a Badajoz como "bien fortificada, abundante en frutos, cultivos, ganedo y miel" (L. MOUNA, Una descripción anónima de al-Andalus, 2 vols., Madrid, 1983, p. 60). Yaqab ee refiere a los siguientes iqlim o nahiya de Badajoz: Asqaliya, Anbal, Barminis, Bayyan (G. ABD AL-KARJM, Yaqut, Pp. 73, 90, 114 y 115, $n^{\circ} 27,46,76$ y 108), Al-Wadi, Kala', Ru'uya y Sasano (Fuentes, pp. 151-152). También de Mérida nos habla Yaqub como ciudad que cuenta con varios nawahi y de la que dependen, además de cartillos, alquerías (G. ABD AL-KARIM, Ibid., p. 275, $n^{2} 333$ ). En el siglo $X$ aparocen dos aldeas, es docir, alquerins, de Mérida en las fuentes árabes, peso a eu cardeter selectivo (IBN HAYYAN, Crónica del califa 'Abderrahman III an-Nasir, p. 102). 
misma villa, pero se despobl6 por consecuencia de revoluciones"113. La noticia que tenemos de que en el 849 el Tajo se desbordo e hizo desaparecer dieciocho pueblos nos hacen pensar en una Extremadura del Tajo con más centros de población de los que habría en los siglos XII y XIII ${ }^{114}$.

Aunque de modo hipotético, los planteamientos anteriores nos permiten unas ideas de partida que pese a ser genéricas no por ello son menos firmes. Diversos indicios nos hacen suponer que el poblamiento en la etapa final de la Extremadura musulmana tuvo una intensidad variable y unas características diferentes en las distintas zonas. Sobre una de ellas, la Siberia y la Serena oriental (que hemos considerado una especie de marca defensiva creada por los almohades) no hay ninguna duda de que nos encontramos ante una comarca con un bajo indice de ocupación o lo que es lo mismo, con escasos centros de poblamiento y una muy baja densidad demográfica. En ella se concentran la casi totalidad de los casos en que se reparte en proporciones determinadas la distancia entre dos centros. Sólo los terminos de Benquerencia y Capilla aparecen delimitados muy parcialmente por accidentes geográficos ${ }^{115}$. A Almorchón se le asigna una extensión radial de una legua salvo en dirección a Capilla, en que la distancia se divide por la mitad. Los problemas de límites entre Alcocer y Peña se solucionan con la división del espacio que les separa (reciben respectivamente dos y un tercio respectivamente). En cuanto a Muro, aunque su término se fija, como consta en la delimitación de Capilla, en un documento concedido

${ }^{113}$ Geografia, p. 170. El despoblamiento de este barrio debió fragüarse bastante avanzado el siglo XI (F. VALDÉs, La alcazaba de Badajoz, pp. 67-74).

114 Fuentes, I, 385 (Obviamente, estos pucblos no tenían que situarse necesariamente en Extremadura).

115 J. GonZÁl.FZ, Feınando III, docs. 575 (Capilla) y 680 (Benquerencia). El caso de Capilla es sintomático por el elcvado número de términos con los que limita: "versus partem Guadiane sit terminus Capelle usque ad metas tennini de Muro, que sunt nominate in privilegio plumbato quod ego dedi archiepiscopo Toletano, deinde dividat terminum Capelle per medium cum Navis que dicuntur vulgariter Navas del Cuerpo; cum Chilón dividat per medium usque ad sumitatem serre; cum Sancta Eufemia dividat per medium, ita quod veniat per metam directum usque ad terninum de Gahet; cum Gahet dividat tenninum hoc modo, quod Gahet habeat duas partes termini et remancat tercia pars Capelle, et in esto directo sint mete per sumitatem serre usque ad serram que dicitur Dos Hermanas, et de serra ista que dicitur Dos Hermanas sint mete usque ad medietatem vie que cst inter Capellam et Almorchón; et Capellam et Almorchón dividant terminum per medium, et de meta ista sit usque ad medietatem de Capella et de Amassatrigo; et Capellam et Amassatrigo dividant terminum per medium, et de meta ista veniat por directum usque ad sumitatem serre, et per sumitatem eiusdem serre sit usque ad terminum de Muro unde incepetunt tennini limitari". Para las restantes delimitaciones de térninos en esta zona, ef. J. GONZÁLEZ, Mbíd., III, doc. 579, y I. J. ORTEGA Y COTES, lbid., doc. 33, p. 105-106. 
a la catedral toledana (no se conserva), no sabemos como se realizo. Por tanto, en todos los casos de la zona se utiliza de modo exclusivo o fundamental la división salomonica de la distancia entre dos centros habitados. No se trata de espacios efectivamente ocupados, sino que junto a un radio posiblemente corto en que el paisaje estaba humanizado habría casi con seguridad unos extremos amplios sin explotar. Por tanto, estamos ante una zonar con posiblemente escasos centros de poblamiento al margen de los castillos que aparecen en las fuentes ${ }^{116}$ y que, consecuentemente, tendría una densidad demográfica muy inferior a la de otras comarcas extremeñas. Todo ello ratifica nuestra idea de una poblamiento fundamentalmente defensivo y reciente.

La vertiente meridional del Tajo presenta unas caracteristicas diferentes a la Siberia y la zona oriental de la Serena. Como hemos señalado ocupa un papel muy distinto en las vías de comunicación musulmanas y cuenta con centros que se remontan al periodo romano. Es un territorio fronterizo, pero no marginal. Por ello, la frontera ha influido en él de modo distinto. La información que tenemos sobre límites en esta zona es más limitada que sobre la anterior. Sólo contamos con un ejemplo tardío (1264) de división por la mitad de la distancia entre dos centros de población (Azagala y Piedrabuena) ${ }^{117}$. Esta circunstancia nos informa de que esto no es algo desconocido en la vertiente meriodional del Tajo. El que sea algo único tampoco tiene mucha importancia si se tiene en cuenta la poca información que tenemos en este espacio sobre delimitación de términos. De hecho, al margen de Azagala y Piedrabuena, solo contamos con información relacionada con Cáceres y con Monfragüe $e^{118}$. Este castillo aparece delimitado por ríos como el Almonte o el Tajo, por el término de Alconétar y por un topónimo (Cabezas de Valero). Los importantes ríos que lo limitan facilita logicamente el que pueda precisarse el alfoz. Se trata de un término amplio para un pequeño castillo como el de Monfragüe. El caso de Cáceres es significativo. En la delimitación del término aparecen topónimos

\footnotetext{
${ }^{116}$ En la delimitación de Capilla aparecen Amasátigo (entre Almorchón y Muro) y Navas del Cuerpo (entre Muro y Chillón), los dos únicos centros de esta zona que no constan que estén fortificados.

117 I. J. ORTEGA Y COTES, Ibid., doc. 35.

$118 \mathrm{~J}$. GonZÁLEZ, Fermando III, III, doc. 742, año 1246 (Monfragüe); P. LUMBRERAS VALIENTE, lbid., pp. IX-X. El término de Montánchez es donado con su términos "novis et antiquis", sin que se especifiquen éstos (J. GONZÁLEZ, Alfonso IX, II, doc. 620).
} 
que podrían ser poblaciones, como Alcuéscar o Talaván, pero esto no es seguro, pues a través de las fuentes cristianas no puede ratificarse. Al margen de estos dos puntos, sólo el Casar del conde Don Gonzalo se refiere con seguridad a un poblamiento de carácter no fundamentalmente defensivo. Sin embargo, llama la atención el elevado número de torres y atalayas mencionadas. La delimitación del extenso término de Cáceres se hace posible, por tanto, por el sistema defensivo articulado por los musulmanes. Es esto, y no una intensa ocupación demográfica, lo que hace nítidos los límites. Aunque es posible que algunas poblaciones musulmanas hayan desaparecido sin dejar ninguna huella en la documentación, el término de Cáceres, que se extiende a lo largo de mil quinientos kilometros cuadrados, parece despoblado en el momento de su conquista y asi continuará hasta finales del XIII, cuando empiezan a desarrollarse sus aldeas. La imagen que las fuentes cristianas nos ofrecen de Trujillo en el momento de la ocupación cristiana e inmediatamente después es muy similar, y todo ello en un alfoz considerablemente más extenso que el de Cáceres ${ }^{119}$.

Las poblaciones que no aparecen como castillos o ciudades fortificadas son muy escasas en esta zona. Podemos citar como posibles poblaciones Azafrán o Zafra, posiblemente la actual Zarza de Montánchez (al igual que en otros casos no aparece claro si es un topónimo o un lugar poblado), y Brozas, que quizás existiese en la época musulmana, a juzgar por su temprana mención en las fuentes cristianas ${ }^{120}$.

Distinta parece ser la situación en la que hemos definido como zona de retaguardia. Sólo la delimitación de Mérida y Alange se hace dividiendo la distancia que les separa en una proporción determinada: Mérida consigue tres quintos por el resto para Alange ${ }^{121}$. Frente a esta excepcion resalta el

119 J. L. MARTIN MARTIN, La villa de Cáceres y sus aldeas. Notas sobre el origen y mantenimiento de una diferenciación socioeconómica, "Norba", I (1980), p. 220. C. NARANJO, lbid., p. 89, calcula en unos siete mil kilómetros cuadrados lá extensión del término de Trujillo, pero todo hace pensar que es una estimación excesiva. M* A. SANCHEZ RUBIO, El concejo de Trujillo y su alfoz en el tránsito de la Edad Media a la Edad Modema, Cáceres, 1991 (tesis doctoral inédita), I, pp. 18 y 20, la ha rebajado a $3000 \mathrm{~km} 2$ para el siglo $X V$, a lo que habria que unir algunas desmembraciones. Solo desde mediados del aiglo XIV la información dela que disponemos nos permite conocer el poblamiento de este alfoz, y en cualquier caso en este momento era escaso (Ibld., pp. 43-56).

120 J. GONZALEZ, Alfonso VIII, II, doc. 520; B. ChAVES, Apuntamiento legal sobre el dominio solar de la orden de Santiago en todos sus pueblos, Barcelona, 1975 (edic. facrímil), p. 35 r.; I. J. ORTEGA Y COTES, Bid., doc. 18, p. 43.

121 J. GONZÁlez, Alfonso $D X$, II, doc. 600. 
relativamente elevado número de casos en que se conceden los términos de la época musulmana, no concretados por conocidos, o se delimitan a través de diversos topónimos. Lo primero sucede con Alange, Hornachos o Reina $y$, lo que es muy significativo, con Benquerencia en relación con Hornachos y Sevilla ${ }^{122}$. Contamos además con las delimitaciones de Badajoz, Mérida, Montemolín y Reina. Estamos ante términos extensos, lo que hacía más difícil la existencia de referencias conocidas. Es muy llamativo que este conocimiento del terreno no se debe tanto a una estructura defensiva como a una mayor ocupación del término. En la carta de confirmación de Alfonso $\mathrm{X}$ del alfoz dado por Alfonso IX a Badajoz, sólo aparecen dos atalayas y ninguna torre; igual de interesantes en este sentido son las delimitaciones de Mérida y Montemolín. En el primer caso aparecen igualmente sólo dos atalayas, una de las cuales (la del Naharro) se cita también en el segundo. En la fijación de los términos de Reina aparece una única atalaya (la del puerto de las Calaveruelas) ${ }^{123}$.

Junto a estos elementos de carácter indirecto, la información directa que nos ofrecen las fuentes cristianas en los primeros decenios después de la conquista apunta en la misma dirección. Los centros de poblamientos sin un carácter especialmente defensivo son mucho más numerosos en el valle del Guadiana. Relacionados con Badajoz aparecen Luchena y Cantiñana (antes de la conquista); en la delimitación de su alfoz se citan las siguientes posibles poblaciones: La Codosera, Loriana, Cabezas de Maimona, Cuenco, Nodar, Torres y Cuerna; y hacia 1255, La Codosera, Ugüela, Gévora, Benavente, Campomayor, Corroches, Almendral y Olivenza ${ }^{124}$.

En la delimitación de Mérida aparecen toponimos que quizás fuesen poblaciones: Aljucen, Casalem Rubeum, Feria, Zafra y, nuevamente, Cabezas de Maimona; no parece suceder lo mismo en el caso de Reina, pues los que se citan no tienen nada que ver con futuras poblaciones; en 1255 ,

122 J. GONZALEZ, Femando III, III, docs. 553, 715 y 739.

123 E. Rodriguez AMAYA, lbld., pp. 11-12; J. GonZÁlez, Alfonso IX, II, doc. 600, y Femando III, III, doc. 763; B. CHAVES, Ibid., fols. 9 v.-10 r.

${ }^{124}$ A. F. AGUADO DE CÓRDOBA, Ibid., doc. 4, pp. 6-7; E. RODRIGUEZ AMAYA, Ibid., pp. 11-13; I. J. ORTEGA Y Co'TES, Ibid., doc. 13, p. 121; F. SANTOS Coco, Ibid., VIII (1934), docs. 13 y 14. Posiblemente Olivenza no existiese en epoca musulmana: una reclameción del concejo de Badajoz en 1278 la presenta como poblada "de nuevo" (expresión que no es concluyente) junto con otras poblaciones por la orden del Temple en territorios sustraídos a Badajoz (E. RODRIGUEZ AMAYA, lbid., p. 17). 
Calamonte cuenta con un espacio agrario perfectamente organizado ${ }^{125}$. En el documento en que se dona y delimita Montemolín se alude a la alquería de Benasgeth. En 1256 se menciona, en un problema de diezmos, a Burguillos, que aparece antes en relación con Reina ${ }^{126}$.

En conclusión, pese al carácter poco claro de gran parte de la información, todos los indicios apuntan a que la zona de retaguardia serfa la más poblada de Extremadura. Su poblamiento no serfa estrictamente defensivo sino que contarfa a la vez que con ciudades y castillos fortificados con centros de explotación rural agraria y/o pecuaria. Esto posibilita el conocimiento exacto de términos muy dilatados, que no aparecen definidos por puntos de finalidad exclusivamente defensiva como torres y atalayas.

\section{ESTRUCTURAS SOCIALES Y ECONÓMICAS}

La situación fronteriza influyo, al igual que en el poblamiento o en la estructura defensiva, de modo muy importante en la realidad socioeconomica de Extremadura.

En el campo estrictamente social, la frontera va ligada al botín, la rapiña y las razzias enemigas. La incidencia de este aspecto es muy similar en la zona cristiana y en la musulmana, pese a las grandes diferencias que ofrecen ambas sociedades. En función de la correlación de fuerzas de los grupos en disputa, la frontera y la rapiña puede ser una fuente de riqueza 0 de empobrecimiento. En cualquier caso, bien en grandes campañas o en pequeñas razzias de grupos limitados es normal que haya alternancias, de modo que siempre el peligro está presente. En general, la frontera ofrece con los almohades unas características muy diferentes a las que ofreció con los almoravides: no se da con éstos un predominio tan claro en el terreno militar (salvo entre Alarcos y Las Navas de Tolosa habrá un relativo equilibrio) y la proliferación de pactos debió producir un fuerte alivió a los sociedades fronterizas, puesto que debieron limitar las operaciones de los concejos cristianos y las ciudades o castillos musulmanes. El periodo que nos ocupa empieza y términa para los musulmanes en general y para los musulmanes extremeños en particular con el signo de la derrota. Sólo en

\footnotetext{
${ }^{125}$ 1. J. ORTEGA Y COTES, Ibid., doc. 14, pp. 88-90; cf. nota 123.

${ }^{126}$ Cf. nota 123; igualmente, A. F. AGUADO DE CÓRDOBA, Ibid., doc. 2, p. 193).
} 
los años finales del siglo XII y la primera decada del XIII el predominio musulmán es claro. En cualquier caso, las derrotas cristianas suelen ir seguidas de pactos con los almohades. Por ello, si todo parece indicar que hasta que los almohades ponen orden en Extremadura los cristianos debieron seguir con operaciones de rapiña por medio de los $\operatorname{concejos}^{127}$ o de Geraldo Sempavor, no parece que se repitiese la situación inversa en los momentos de predominio almohade. Tras Las Navas, los musulmanes extremeños debieron sufrir numerosas campañas leonesas que debieron incidir muy negativamente en la producción de la zona, al menos en la agricultu$\mathrm{ra}^{128}$. Las expediciones musulmanas sobre zona cristiana son menos numerosas, tienen como finalidad la represalia y/o el afianzamiento de la Extremadura musulmana pero al no haber un deseo de expansión no gozan de la continuidad ni la tenacidad de las cristianas. De este modo, la Extremadura musulmana, y especificamente la que se sitúa en primera línea, que se extiende entre el Tajo y la divisoria de aguas entre este río y el Guadiana, y sobre todo en su parte occidental, zona de expansión leonesa, debió sufrir de modo muy negativo la situación de frontera. Las posibilidades de botín en la parte cristiana parecen limitadas a la vez que las expediciones cristianas debieron ocasionar destrozos y posibilidades de enriquecimiento para sus autores. De este modo, la frontera debió tener una incidencia más positiva para la zona cristiana que para la musulmana.

La coyuntura político-militar por tanto no resulta favorable a la Extremadura musulmana, concebida según todos los indicios con una finalidad casi exclusivamente defensiva. Sin embargo, de esto no debe deducirse que las estructuras sociales de la frontera musulmana fueran menos adecuadas. Ya hemos señalado que había muchos elementos en común al lado de importantes diferencias. La Extremadura musulmana estaba dotada de hábitos fronterizos en los que la rapiña era una práctica habitual. Al-Idrisi, al

\footnotetext{
127 Nada impide pensar que actuaciones como la destrucción apresurada del castillo de Albalat por salmantinos y abulenses tras la conquista de Coria o expediciones del tipo de la que realizan los salmantinos por la zona de Badajoz, con lucrativos resultados, antes de la toma de esta ciudad altoextremeña no tengan continuidad en estos momentos de desconcierto y desorganización en la Extremadura musulmana (Cf. Chron. Adeph. Imper., pp. 126 y 95-96 respectivamente).

128 En 1218, Alfonso IX realiza una expedición contra Cáceres, en la que destruyó "todas las cosas que eran en derredor de Caçercs, asi como arbores, viñas y mieses", y otra contra Badajoz en que actúa de la misma manera (LUCAS DE TUY, Ibld., p. 422). Del mismo modo actuaría en la campañas que desde 1213 realizó en Extremadura, pues contituye una norma general de la guerra medieval, verdadera guerra económica tendente a producir escasez.
} 
igual que las fuentes cristianas, nos informan con suficiente claridad sobre el tema. Aunque esta información se centra en el periodo almorávide, uno de los periodos de mayor predominio musulmán en la península, no hay razones para pensar que las estructuras y hábitos sociales hubieran cambiado; distinta cuestión es que la cambiante coyuntura haga a estos últimos mucho menos efectivos en el campo musulmán. A través de las fuentes señaladas, sabemos que tanto infantes como jinetes tenfan entre sus actividades el realizar razzias en tierras cristianas. Al-Idrisi cita a Medellín, Trujillo y Cáceres; la Chronica Adephonsi Imperatoris se refiere a Coria y Albalat ${ }^{129}$. Dado que en estos momentos Coria no estaba conquistada, las penetraciones de los aventureros musulmanes podían llegar hasta muy al norte, incluso al Duero, y producir numerosos daños en los concejos de la Extremadura histórica. Esto explica el apresuramiento de Avila y Salamanca en destruir Albalat.

Pese a una táctica mucho más defensiva de la Extremadura almohade respecto de la almorávide, las estructuras sociales fronterizas no debieron cambiar. A través de la información citada nos podemos hacer una idea de las mismas. La frontera musulmana contaría con hombres preparados para la guerra para los cuales la rapiña sería una de sus posibles fuentes de ingresos. Esta adecuación militar afectaría a muchos, por no decir casi a todos, los que poblaban las zonas más expuestas, pues no de otro modo se explica la continua alusión a los peones como participantes en las razzias. Las ciudades y, suponemos, los castillos contarían con una elevada autonomfa. La existencia de guarniciones enviadas por el gobierno central no parece que fuera algo habitual, aunque no puede excluirse esta posibilidad para las ciudades más importantes ${ }^{130}$. Sin embargo, como hemos señalado, la pericia y los hábitos militares de los habitantes fronterizos de la Ex-

\footnotetext{
129 Al-Idrisi nos dice que los caballeros y peones de Medellín "hacen incursiones y razias en el país de los cristianos", al igual que los de Trujillo, para los cuales habla de "continuas incursiones", señalándonos que "Ordinariamente viven del merodeo y se valen de ardides"; Cáceres parece ser punto de reunión para realizar estos saqueos (Geografia, pp. 177 y 178); no sería el único, o al menos no el único punto desde el que se realizabam expediciones, pues Coria y Albalat, amparándose en sus numerosos caballeros y peones, "quotidie debellabant totam Extrematuram usque ad flumen Dorium", cumpliendo el mismo papel que el castillo de Oreja en la zona toledana (Chron. Adeph. Imper., pp. 84-85).

130 Ibn Idari nos infonna de que en 1169 se establecieron en Badajoz "un grupo de almohades y soldados andaluces", pero Badajoz, un centro destacado por su importancia política y militar, no estaba en la primera línea fronterizu, aunque en ese momento se temía por la seguridad en toda la Extremadura musulmana (Fuentes, I, 404).
} 
tremadura musulmana debieron utilizarse más en labores defensivas que ofensivas. De todos modos, la pequeñas expediciones no aparecen en las fuentes sino muy excepcionalmente. Es precisamente este capital humano lo que permitió que lugares como Cáceres se convirtieran en inexpugnables, o que lugares como Capilla protagonicen resistencias sorprendentes ante huestes reales cuando ciudades situadas en el valle del Guadalquivir con más habitantes y bien defendidas cayeron con relativa facilidad.

Si la frontera influye en la sociedad de la Extremadura musulmana, también lo hará en el ámbito de la producción. Para esto, son sobre todo las fuentes cristianas las que nos ofrecen información. Lamentablemente, se refiere de modo casi exclusivo al sector primario. En la Extremadura musulmana aparecen dos modelos socioeconómicos diferentes, pese a que ambos intentan reproducir una de las características más constante de toda economía precapitalista: la autarquía económica tanto en el ámbito familiar como dentro de espacios pequeños de tipo comarcal. La frontera sufre una adaptación derivada de su vulnerabilidad tanto real como potencial a la vez que un déficit productivo endémico, como consecuencia no sólo de lo primero sino de la estructura ocupacional de muchos centros de hábitat en los que la actividad militar requiere mucha dedicación. Este déficit productivo aparece varias veces en las fuentes cristianas y es consecuencia, según creemos, de las dos circunstancias que hemos señalado. Es frecuente que la concesión de un punto defensivo vaya unido a la concesión de una renta, bien directa bien en propiedades, que permita al recipiendario resarcirse de las pérdidas de sus posesiones jurisdiccionales fronterizas ${ }^{131}$. En esta situación debió incidir de modo muy fuerte el estado de la infraestructura productiva heredada de los musulmanes.

Además de este defīcit productivo, que no sabemos como se intento paliar en el mundo musulmán (la transferencia retaguardia-frontera se reali-

131 Alfonso VIII concede a la Orden de Trujillo los castillos de Albalat, Santa Cruz, Zuferola y Cabañas y "ad munitionem igilur et manutenentiann perpetuam predictoruin castronum et villarum" le da tres mil maravedís en la greda de Magán (J. GoNZÁLEZ, Alfonso VIII, III, doc. 641); igualmente, Alfonso IX concede a la Orden de Alcántara el cillero de Alba de Tonnes y heredades en Gerna y Moreruela de los Infanzones "ad defensionem frontarie regni mei adversus mauros, et specialiter ac precipue ad tenenteam et ad defensionem de Alcantara" (J. GONZÁLEZ, Alfonso IX, II, doc. 354); en una bula papal de 1225 en que se contesta a la petición de ayuda de Alfonso Tellez para la defensa de Alburquerque se señala que "propter guerram eorum continuam et obsidionem, etiam deficiente pane et camibus et aqua dumtaxat" (M. R. MARTINEZ Y MARTINEZ, lbid., p. 375). Las tres documentos citados afectan a lugares hasta poco untes controlados por los musulmanes que conservarían una infraestructura productiva muy similar a la que mantenian con éstos. 
za en el mundo cristiano sobre la base de la unidad jurisdiccional, algo que no existe en la Extremadura musulmana, pues ciudades y castillos no son parte de conjuntos patrimoniales privados), la frontera incidirá en el peso de los diversos componentes productivos del sector primario. Las formas notariales de donación de lugares de los documentos cristianos nos muestran un espacio con prados, montes y pastos, que contrasta abiertamente con otras formas notariales utilizadas para otros lugares más meridiona$\operatorname{les}^{132} \mathrm{La}$ agricultura no aflora debemos pensar que por su peso inferior; esto viene ratificado por la práctica ausencia de donaciones de heredades agrarias en las zonas fronterizas musulmanas tras su control por los cristianos. Sin embargo, no estaría ausente tanto la producción cerealícola como la vid ${ }^{133}$. En definitiva, la ganadería tendría un papel considerable en las zonas directamente fronterizas. Aunque no encontramos muchas alusiones directas a este hecho (concesión de Capilla por Fernando III, donación de rentas en Trujillo por Alfonso VIII) en las fuentes cristianas todos los indicios apuntan en este sentido ${ }^{134}$. De este modo, el modelo económico fronterizo de las tierras musulmanas aparece sensiblemente similar al de las

132 Alcántara se concede en 1217 "cum suis directis, portaticis, molinis et aqueductibus, corum canalibus, piscationibus, et aquis earum, pratis, pascuis, exitibus et regressibus, et cum quanto ibidem ad prestitum hominis esse videtur" (J. GONZÁLEZ, Alfonso IX, II, doc. 346); Alcocer en 1245 "cum ingressibus et egressivus, cum montibus, nemoribus, fontivus, rivis, aquis, pratis, pascuis e cum omnibus terminis, dirccturis et pertinentiis suis" (J. GONZALEZ, Femando III, III, doc. 726); Capilla en 1236 "cum suis fontibus, montibus et pascuis, ingressibus et egressibus et cum omnibus directuris ad eosdem terminos pertinentibus, hoc excepto quod hereditates et loca que ad colendum apta et utilia videbuntur excolantur, cetere vero hereditates serventur inculte ad fanatorum pascua et estremos" (Ibid., doc. 575); y Montánchez en 1230 "cum pratis, pascuis, montibus, fontibus aquis, ingressibus et exitibus" (J. GONZÁLEZ, Alfonso IX, II, doc. 620). Las fonnulas son similares para Benquerencia (Fermando III, II, doc. 680, año 1241), Albalat, Zuferola, Cabañas y Santa Cruz (Alfonso VIII, II, doc. 520, año 1189) o Monfragüe (Fermando III, III, doc. 742, año 1246).

${ }^{133} \mathrm{Cf}$. nota 128. En 1166, Fernando Il dona en Alcántara entre otros bienes una huerta y una viña (J. GONZÁLEZ, Fernando II, p. 391). En 1189, Alfonso VIII concede a la orden de Santiago en Trujillo el diezmo "de omni pane et vino quod in agricultura Turgelli percipio et percipiam in postcrum, et tocius ganati quod in Turgello habeo vel habebo usque in finem" (J. GoNZAIf.Z, Alfonso VIII, II, doc. 519). En 1257, el concejo de Trujillo da al obispo de Plasencia 10 yugadas de heredad (cuatro y seis), amojonándosela hombres buenos (D. SÁNCHEZ LORO, Ibid., pp. 398-399).

134 Estamos informados de que los salmantinos en sus razzias en la zona de Badajoz con anterioridad a la conquista de Coria por los cristianos "ceperunt opes magnas, equos et mulos, camellos et asinos, bobes et vaccas et omnia pecora campi" (Chron. Adeph. Imper., pag. 96); la riqueza ganadera de las zonas musulmanes más septentrionales debería ser aún mayor dado su carácter de bien semoviente. Es posible que la riqueza pecuaria de Trujillo mencionada en la nota anterior fuera de origen musulmán, aunque esto es menos seguro que para la agricultura. Para la donación de Capilla, cf. nota 132. 
zonas cristianas, lo que no deja de ser lógico dada sus parecidas circunstancias. Déficit crónico de la producción, predominio ganadero y menor importancia de la agricultura parecen ser sus caracteristicas.

El valle del Guadiana (excluyendo claro está la Siberia y la Serena oriental) ofrece una realidad diferente. Montemolín es donado a la orden de Santiago "con montes, con fuentes, con aguas, con prados, con rios, con pastos, con arboles et con olivares, et con heredat de lavor, et con montadgos e con portadgos", y Hornachos, "cum montibus, fontibus, rivis, aquis, pratis, pascuis, vineis, terris cultis et incultis, arboribus, et cum pertenenciis suis" ${ }^{135}$. En Mérida hay viñas (una aranzada) para todos los pobladores $^{136}$. Las concesiones de heredades poco después de la conquista cristiana también nos ilustra sobre el espacio agropecuario. Estas se ubican fundamentalmente en Badajoz y Medellín ${ }^{137}$ y suelen constar de heredades de pan llevar, viñas, molinos o aceñas y huertos (as); menos frecuente es la concesión de olivares. Los espacios agrarios del primer tipo tienen una extensión expresada en yugadas por las aranzadas usadas para viñas, huertos (as) y olivares. Estamos, por tanto, ante un predominio en extensión de las tierras de pan llevar, que se constituyen como el cultivo fundamental, y ante el uso de grasas vegetales, lo que contrasta con el consumo casi exclusivo de las animales en el mundo hispanocristiano. El espacio agrario esta sufientemente ocupado como para que las explotaciones se presenten con una extensión determinada y con límites precisos.

¿Qué papel tendría la ganadería en esta zona más poblada y con más peso de la agricultura, que con toda seguridad se constituirfa como la dedicación económica fundamental?Las fórmulas notariales citadas de Montemolín u Hornachos unen a las menciones de espacios agrarios referencias a pastos y montes. Debemos suponer que la ganadería no estaría ausente e incluso que el abundante botín gañadero que antes de la conquista de Coria obtuvieron los salmantinos en la zona de Badajoz sería consecuencia de un

135 Femando III, III, docs. 553 y 763. Las fómulas notariales utilizadas para Alange (único lugar de la zona que ve como el espacio que le separa de Mérida se divide entre ambos en una proporción detenninada y no por referencias toponímicas) o Reina (se mencionan molinos) (Ibid., III, docs. 715 y 739) no son similares y son más parecidas a las de Alcántara, Montánchez o Alcocer.

${ }^{136}$ A. F. Aguado DE CÓRDOBa, Ibid., doc. 4, p. 107.

137 I. J. ORTEGA Y Cotes, Ibid, doc. 14, pp. 88-90; F. SANTOS Coco, Ibid., I (1927), doc. 4 y 6 (años 1255 y 1256); J. GONZÁLEZ, Fermando III, III, docs. 531 y 550 (años 1234 y 1235). 
riqueza pecuaria importante que debio mantenerse durante el siglo siguiente.

Mayor ocupación del espacio y densidad, consiguiente mayor peso de la agricultura (todo esto facilitado por su ubicación en la retaguardia) y una importancia, sin embargo, no desdeñable de la ganadería son los rasgos que definen la producción del sector primario en el valle del Guadiana.

$\mathrm{Si}$ sobre la producción y el espacio agropecuarios las fuentes, cristianas fundamentalmente, nos permiten esbozar unas líneas, no por generales menos sólidas, sobre el comercio la información que tenemos es prácticamente nula. En nada nos ayudan para su conocimientos las fuentes cristianas y las musulmanas son muy parcas en ofrecer detalles. Simplemente sabemos que en Trujillo habfa bazares bienes surtidos y que eran abundantes en Elvas $^{138}$. No deberfan tener una situacion muy distinta otras poblaciones de una entidad muy similar a éstas. Con seguridad, el comercio estaría en estrecha relación con las vías de comunicación. En este sentido, Badajoz sería el centro más importante, como corresponde igualmente a su entidad demográfica. La actividad comercial no estaría ausente en un cierto grado en todos las demás poblaciones que contaban con contingentes demograficos importantes. Son aquéllas que reciben la denominación de madina $o$ que pese a aparecer como castillos se aproximan a ser consideradas como tales. En este grupo se situarian, además de Trujillo o Elvas, Alcántara, Cáceres, Jerez o Mérida. Poco más que estas generalidades podemos señalar.

\section{CONCLUSIONES}

La Extremadura musulmana aparece con un perfil claro durante el periodo almohade, que viene definido por el nuevo papel estratégico que juega durante la segunda mitad del siglo XII y primer tercio del XIII. En este sentido, este periodo marca en Extremadura una ruptura muy importante con las fases anteriores de la ocupación musulmana. Esta ruptura viene dada por la frontera como hecho que afecta a todos los ámbitos de la sociedad extremeña, y su consecuencia es la creciente capacidad defensiva de los puntos fortificados de la región. De hecho, los almohades la concebirán como un muro de contención frente a unos cristianos que desde la con-

${ }^{138}$ AL-IDRISI, Geografia, pp. 175 y 177. 
quista de Toledo se muestran, y ya no dejarán de hacerlo, como absolutamente peligrosos. Esta realidad cambia la faz de Extremadura, al incidir fuertemente en las características de los núcleos habitados y explicar el desarrollo de algunos de ellos (por ejemplo, el poblamiento de la zona oriental de la provincia pacense). La sociedad extremeña será concebida, por tanto, como una sociedad para la guerra, si bien, en un sentido claramente defensivo pues a los musulmanes en la España medieval siempre les faltó el ánimo expansivo que tenían los cristianos. Esto va a hacer que especialmente algunos centros como Cáceres se defiendan magníficamente de las armas cristianas, lo que exige personas con habilidades y mentalidad bélicas.

La incidencia de la frontera no es algo que afecte de modo homogeneo a toda Extremadura. En realidad, dentro de la concepción de la región como una zona claramente fronteriza, se desarrolla una primera línea, limitrofe con la España cristiana, en donde esta circunstancia marca de modo absolutamente claro las diversas realidades socioeconómicas y políticas, y una segunda, que podemos llamar de modo relativo retaguardia, en donde si bien la labor de fortalecimiento defensivo fue importante las demás realidades no están condicionadas tan fuertemente por la frontera. Se desarrolla, por tanto, en todos los ámbitos una dicotomía marcada entre la zona fronteriza o limitrofe con la cristiana y la retaguardia. La primera aparece como un espacio poco poblado y en donde se acusa un marcado predominio de los centros defensivos. La retaguardia articula un poblamiento más nutrido y en ella la defensa es solo uno de los elementos que condicionan su estructuración. Esto crea una paisaje más humanizado y un mayor peso de aquellas actividades que requieren más cantidad de trabajo como la agricultura. Esta dicotomra no deja de incidir incluso en la predisposición bélica: las aguerridas defensas de Cáceres y Capilla contrastan con la actitud de los habitantes de Elvas, prestos a abandonar la ciudad ante las primeras noticias desfavorables sin esperar a ningún asedio.

Podemos concluir, por tanto, afirmando que lo que dota de especificidad al periodo almohade en Extremadura es el fortalecimiento defensivo de la zona ante la nueva situación estratégica creada por la expansión cristiana hacia el sur y concretamente por la conquista de Toledo y Coria. Este fortalecimiento defensivo es un éxito y no dejará de surtir positivos efectos para la España musulmana. Por todo ello, se desarrollan en la región zonas que podemos considerar auténticas marcas y que son las limítrofes con la España musulmana (vertiente meridional del Tajo y zona oriental de la 
provincia de Badajoz). En cualquier caso, los almohades no irán más allá de una concepción defensiva de Extremadura, que no será suficiente ante el empuje cristiano.

\section{RÉSUMÉ}

L'Extrémadure almohade se configure dans la partie occidentale de la péninsule à la façon d'une avancée musulmane. Le Tajo délimite normalement, pendant tout ce période, la frontière entre les musulmans et les chrétiens, après la conquête définitive de Coria par Alphonse VII. De cette façon, l'Extrémadure musulmàne devient un authentique repère frontalière, même si elle ne présente pas un profit homogene. La zone qui correspond au versant méridional du Tajo possède un caractère tout à fait défensif (il n'apparaît que des forteresses mais aucun village) et possiblement avait une population et une activité économique peu abondante. Des lieux comme Cáceres, facilement conquis par Geraldo Sempavor, deviennent inexpugnables, grâce à l'activité constructive almohade. La vallée du Guadiana maintient une certaine continuité dans sa structure économique,d'après les abonndants villages, ainsi qu'une importante activité agraire. Il s'établie, donc, une dichotomie entre une première zone entièrement frontalière et une deuxième que nous pouvons dénommer, dans un sens rélatif, d'arrière-garde. Les almohades ne passent pas de représenter en Extrémadure une conception simplement défensive et jamais ils n'ont conçu la fortification du lieu comme une étape dans la récupération de la Transierra chrétienne.

\section{SUMMARY}

Almohade Extremadura extended on the western side of the peninsula as the northern most Muslim domain. The Tagus River usually defines the boundary between Muslims and Christians during the period after the final conquest of Coria by Alfonso VII. Thus, Muslim Extremadura becomes a true border area, although it does not present a very homogeneous profile. The area corresponding to the southern bank of the Tagus is clearly 
defensive in character (only fortresses can be found, but not villages) and must have had a small population and scarce economic activity. Places like Cáceres, which was easily conquered by Geraldo Sempavor, became impregnable thanks to Almohade construction. The valley of the Guadiana River maintains a certain continuity in its economic structure, judging by numerous villages and the important agricultural activity. Thus, a dichotomy is established between the first area, which is clearly a border zone, and the second, which could be called in a relative sense the rearguard. In Extremadura, the Almohades do not go beyond the merely defensive and they never conceived the fortification of the area as a stage in the recuperation of the Christian Transierra. 